\title{
Necrópolis altomedievales y despoblación en la provincia de Tarragona, el caso de la Conca de Barberà
}

\author{
Joan Menchon i Bes
}

El estudio del mundo funerario en Cataluña ha proporcionado en los últimos años una importante cantidad de trabajos y publicaciones, aunque el conocimiento es aún fragmentario a pesar de los logros obtenidos.

En este contexto hemos de hacer especial mención a la línea desarrollada por el departamento de Historia Medieval de la Universidad de Barcelona, y como exponente el ya clásico anejo I de la revista Acta/Mediævalia, "Necrópolis i sepultures medievals a Catalunya". Son de gran interés las aportaciones derivadas de las intervenciones del Servei de Patrimoni Arquitectònic Local de la Diputación de Barcelona, y mención aparte se merece la colección Catalunya Romànica, que en sus diferentes volúmenes comarcales, ha expuesto una importante cantidad de datos relativos al período altomedieval. No podemos tampoco obviar las investigaciones realizadas por el Patrimoni Artístic Nacional d'Andorra, en actuaciones en edificios y estaciones arqueológicas de esta época.

Sin embargo por el momento no contamos con estudios profundizados sobre otros temas, aunque algunos han sido abordados desde la historia del arte, como el libro de Xavier Sitges sobre los sarcófagos e inscripciones de la zona del Llobregat (SITJES 1994), O las investigaciones sobre antropología física (JUAN, LALUEZA 1994, pp. 687-691, JUAN 1995, pp. 203-210, VIVES 1990).

Hemos de reconocer también que la mayoria de trabajos procede de la Catalunya Vella, de las provincias de Barcelona y Girona, y de zonas rurales. Hoy por hoy no se han publicado muchos estudios arqueológicos de espacios funerarios urbanos ni del período bajomedieval.

Si nos referimos al conocimiento del mundo funerario del período visigodo, las comunidades hebreas (ROMANO 1970, pp. 50-65; ROMANO 1993-94, pp. 291-315) O de las zonas de influencia andalusí (CURTO et alii 1984, pp. 141-146) los datos que actualmente tenemos son escasos.

Desde hace algunos años estamos estudiando el mundo funerario medieval de la provincia de Tarragona desde una perspectiva arqueológica. Fruto de esta investigación, hemos podido recopilar una importante cantidad de datos tanto del período alto como del pleno y bajomedieval. En este artículo nos centraremos en el comentario de una serie de necrópolis a nuestro entender altomedievales cuya existencia pone, al menos en tela de juicio, la idea de una despoblación entre la invasión árabe-musulmana y la conquista por parte de los condes de Barcelona. Nos centramos en concreto en una comarca de Tarragona, limítrofe con Lleida y Barcelona, la Conca de Barberà, con capital en Montblanc.

La configuración actual de la comarca de la Conca de Barberà corresponde a la división administrativa de 1932, que incorpora zonas de las vecinas comarcas naturales del Baix Gaià y Baixa Segarra. Su extensión es de $648,9 \mathrm{~km}^{2}$ y limita con las comarcas de Urgell, Serrarra, Anoia, Alt y Baix Penedès, Alt y Baix 
Camp, Priorat y Garrigues. Geográficamente pertenece a la Depresión Central Catalana, en una posición marginal y en contacto con la serranía Prelitoral. Los valles se forman mayoritariamente con materiales oligocénicos, blandos y afectados por la erosión de los rios Francolí y Anguera; mientras que las montañas muestran básicamente materiales paleozoicos y triásicos.

La comarca está envuelta por las sierras de Llena y Corregó, que enlazan con el Tallat y Suró, el Codony, la Brufaganya, el Cogulló y Miramar, l'Ermità y los montes de Prades. El valle está atravesado por río Francolí y su afluente Anguera, que desemboca en Tarragona, mientras que en el Alt Gaià al norte, tenemos el nacimiento de este río, que entrega sus aguas al mar en Tamarit, cerca de Altafulla.

Los valles del Francolí y Anguera son las comunicaciones tradicionales de la comarca, aprovechadas por las vías actuales como la autopista A-2. Las carreteras N-240 y C-240, que enlazan con Reus y Tàrrega, y el ferrocarril que une la capital de la comarca con Tarragona, Lleida, Barcelona y Reus. Es por tanto una zona de paso y comunicaciones entre la costa catalana y el traspaís !.

\section{SOBRE LA SUPUESTA DESPO- BLACIÓN ANTERIOR A LA CON- QUISTA FEUDAL}

En 1962 el professor Riu lamentaba el escaso conocimiento arqueológico que se tenía del período de transición entre el mundo clásico y medieval (RIU 1963 pp. 26I-280). El interés de los arqueólogos por el mundo antiguo y la prehistoria, y de los medievalistas por la información documental han dejado este período, pobre en documentación y en restos espectaculares, en una situación de semiabandono intelectual.
Afortunadamente las cosas han ido cambiando, aunque no totalmente. Problemas como la continuidad o ruptura de formas de vida, hábitat o creencias no han sido aún solventados. En la zona que nos ocupa, la llamada Catalunya Nova, uno de los problemas a solventar es conocer qué sucedió entre la invasión árabe-musulmana y la conquista feudal o "reconquista" como se ha denominado tradicionalmente.

La supuesta ruptura que comportó la invasión musulmana es un tema que debe estudiarse con más profundiad en las comarcas tarraconenses (MENCHON 1992 pp. 7-30, 1995 pp. 211-227, 1996 pp. 15-63). La historiografía clásica ha querido ver una despoblación sistemática desde el 7| 3-I4 hasta la conquista feudal. Se ha dicho que los habitantes del país, los llamados hispanorromanos e hispanovisigodos huyeron al Pirineo, de manera que estaría densamente poblado, mientras que el interior permanecería yermo y la costa tendría una baja densidad de población, aunque estable. A partir del siglo IX se iniciaría la ocupación del llano por parte de aprisiadores, iniciativa después absorbida por el poder eclesiástico y condal, que daría pie a la llamada "repoblación".

Sin embargo últimamente esta visión ha entrado en crisis. Se empieza a revisar la imágen catastrofista de la conquista islámica, que no comportaría la desbandada de la población, sino que desballestó definitivamente el ya débil aparato de poder visigodo, con la huida de al menos parte de la aristocracia laica y eclesiástica. Realmente la ausencia de documentación escrita, así como de una investigación arqueológica sólida, han llevado a pensar en despoblación, cuando quizás habría que pensar en una ausencia de poder organizado, de manera que no se generaría la obsesión y único instrumento de trabajo de ciertos medievalistas: la documentación de archivo (cfr. BALAÑ̀̀ 1992, 1993a).

\footnotetext{
I Buena parte de estas reflexiones y datos proceden de nuestra tesis doctoral en elaboración dedicada al estudio del mundo funerario de las comarcas tarraconenses y dirigida por el Dr. Carlos de la Casa. El estudio de las necrópolis de losas de la Conca de Barberà se ha visto reflejado en fondo, que no en forma en MENCHON 1996 y el inventario de necrópolis en la obra colectiva Catalunya Romànica vol. XXI (MENCHON, TOSAS 1995, pp. 590-59I).
} 
Es plausible pensar en una "ruralización" de la población, una huida al campo y la montaña cercana, donde "adoptà unes formes d'organització de tipus pre-romà, comunitáries o tribals" como supone Riu Barrera (1991 pp. 265-272).

La huida de las autoridades hispanorromanas, o al menos una parte, es un hecho cierto, como el del obispo Próspero de Tarragona y sus diáconos. Al referirse a Tarragona y al Camp de Tarragona (comarca natural formada por el Tarragonès, Alt Camp y Baix Camp) el medievalista E. Gort (1989, pp. 34-62) es claro. Siguiendo la línea de Virgili (1984) y Recasens (1975, pp. 30-46), no acepta la idea de un despoblamiento después del 7|3-7|4, ni siquiera la destrucción de la metrópoli Tarraco: "Certament, sembla que hi hagué époques d'abandonament, així com també sembla un fet demostrat -o si més no, acceptat- l'anorreament progressiu de la ciutat des de l'época visigòtica i la seva pràctica desaparició com a ciutat -com a centre de poder, o administratiu, no pas com a nucli de població- en temps dels sarraïns. Però ni l'abandonament possiblement no va ser complet -tret d'alguns períodes concrets- ni va durar un espai tan dilatat de temps com sempre ens havien dit".

Anton Virgili defiende la hipótesis e incluso la posibilidad de una cierta colonización musulmana de Tarragona (VIRGILI 1984, pp. 7-36) 2', rota a partir del siglo IX por las expediciones francas. La narración de la expedición de Luís el Piadoso (804-806) le hace suponer que en Tarragona había población, y en el Camp incluso núcleos rurales y castillos. En el siglo IX ya no parecería posible una colonización andalusí, por las circunstancias históricas, bastante turbulentas, aunque la violencia sería vigente en períodos cortos de tiempo que llevarían a paréntesis de poblamiento en una zona donde grupos humanos podrían vivir o subsistir en períodos de baja belicosidad.

Ramon Martí, en el caso del Penedés, es de la misma opinión: matizar e incluso negar el vacío de población entre la invasión árabe-musulmana y la conquista feudal (MARTí 1993, pp. 32-35).
En los últimos años algunos investigadores han proporcionado datos que apuntan en contra de la idea de la despoblación. El equipo de Miquel Barceló defiende la idea de una colonización árabe y bereber en el límite sur de la Catalunya Vella, en el Penedés (BARCELÓ 1988, pp. 14-17); también se supone un poblamiento prefeudal en el Vallés y en el obispado de Girona, Martí apuesta por la continuidad de las villae como elemento básico de la propiedad señorial anterior al siglo XI (MARTí 1988, pp. 153-182).

Para apoyar esta idea es necesario, dada la falta de documentación escrita, buscar la de tipo arqueológico, casi desconocida en muchos casos, acercarse a la toponimia, que apunta a la existencia de un cierto poblamiento que permetiría la perduración de topónimos romanos, prerromanos, árabes, bereberes y mozárabes (AMIGÓ 1989). Y, aunque en principio la documentación escrita de este período en la zona que nos ocupa es escasa, la relectura de ciertos textos de principios de conquista muestra la existencia de este poblamiento prefeudal, como es el caso que estudia Virgili en el valle del Gaià (VIRGILI 1991).

\section{LA CONCA DE BARBERÀ ENTRE LA ÉPOCA ROMANA Y LA CON- QUISTA FEUDAL}

La Conca de Barberá se podría definir en cierta manera como una zona de paso entre el Camp de Tarragona, la costa, y los llanos de Lleida y el valle del Ebro. En efecto, la Via Aurelia que unía las ciudades de Tarraco e llerda era el eje vertebrador de las comunicaciones entre la capital romana y el traspaís.

Conocemos una importante cantidad de asentamientos de época romana, aunque no hay un estudio exhaustivo al respecto, si bien una de estas villae, la de Plans d'En Jori en Montblanc, ha sido recientemente excavada.

Pese a esta falta de datos, nos encontramos con elementos que llaman la atención, como

2 Posteriormente da la impresión que el autor se muestre más escéptico. Cfr. VIRGILI 1995, p. 28. 
la presencia de niveles medievales sobre yacimientos romanos, hecho que permitiría plantear la cuestión de la reocupación o continuidad de hábitat.

Estas villas se sitúan en los valles de los ríos Francolí, Anguera y Corb (ADSERIAS et alii 1984 pp. 58-60, 1989a) y algunas de ellas ofrecen amplias posibilidades de estudio, como Pedrinyá, los Borrells o Riudabella, de donde procede una inscripción del siglo II, o la Granja Mitjana (ARBÓs 1983 pp. 45-59; MAYER, POBLET 1992 pp. I43-I50, MARCET 1983, pp. 17-18; RAURET 1962 pp. 25I)

En cuanto al régimen jurídico de la Conca de Barberá en época romana, Benet defiende la posibilidad que se trate de un municipium rural disperso, en cierta manera al estilo del Municipium Sigarrensis (BENET 1984 pp. 6I-66, PERA 1994 pp. 323-325). Esta sugerente hipótesis necesita, sin embargo, un elemento arqueológico o epigráfico que la refrende. Si bien se ha intentado reconstruir el catastro romano de la comarca, los resultados han sido infructuosos (PERIS et alii 1989 pp. 151 - 168).

Poco conocemos del mundo funerario en época romana. Sabemos de enterramientos de tegulae en la Granja Mitjana, Riudabella, con un sarcófago excavado recientemente ("Noticiari" 1994 p. 197), y otro en los Palaus, en Vallfogona (DUCH 1979 pp. I17-129).

Menos aún podemos decir del período visigodo. Tan sólo contamos con algunas hebillas y fíbulas, la más conocida es la procedente del Tossal de les Venes, cerca de Montblanc (ESPELT, POBLET 1978, pp. 25-32). Apareció en un abrigo, casi a flor de tierra según los descubridores, y se trata de una pieza liriforme datada en el siglo VII. Ejemplares similares se han localizado en la necrópolis paleocristiana de Tarragona, y en la villa de los Munts, en Altafulla (AMO 1994 pp. 167-180; BERGES 1969-70 pp. 140-150).

La aparición de la pieza en un abrigo, siguiendo la versión publicada, abre las puertas a un tema que ya empieza a plantearse, la ocupación troglodítica en época visigoda. Últimamente se han documentado cuevas utilizadas en éste período, como hábitat eremita, como perduración de espacios sagrados o como lugares simplemente frecuentados e incluso habitados (cfr. PADRÓ, VEGA 1989 pp. 9-53; REYES 1993 p. 24; COLL et alii 1995 pp. 169-183).

En el monasterio de Poblet se localizan algunas piezas escultóricas de época visigoda que han llevado a pensar equívocamente en la existencia de un precedente monástico de este período. Sin embargo, su procedencia no es clara, y las excavaciones realizadas en el cenobio muestran que su fundación es ex novo (VIVES, GIBERT 1964 pp. 191-202, MUÑOZ et alii 1995a pp. 293301, MACIAS et alii 1995 pp. 93-103).

Sans Travé indica dos elementos que hacen pensar en la continuidad de población (SANS TRAVÉ 1995, pp. 429-431). En la villa de los Borrels (Barberà de la Conca) se han localizado materiales cerámicos romanos, islámicos y medievales. Apunta la idea que esta villa sea la residencia de un tal Barberanus, que daría nombre tanto a ella como a la comarca, el Campus Barberanus de los primeros documentos medievales y que se podría tomar como un territorium visigodo. El otro elemento es la villa de Pedrinyà, mencionada en los primeros documentos feudales como villa de Pedrignano, un personaje tal vez cristiano, Pedro.

Descraciadamente en la Conca no tenemos muchos datos del período musulmán. Formaría parte de las últimas estribaciones o límites del Al-Tagr al Aqsa o marca superior de Al-Andalus. La zona estaría dividida, probablemente entre la influencia de Tortosa y Lleida, dependientes de Zaragoza, con unos límites difíciles de precisar pero que habría que relacionar con los accidentes geográficos (BALAÑÀ 1992).

Últimamente P. Balañà ha estudiado la toponimia andalusí de diversos puntos de la comarca y defiende la etimología árabe de algunos topónimos mayores: Llorac, Albió, la Cirera, Montargull (BALAÑÀ 1984 pp. 45-5।, 1988 pp. II23, 1993b pp. 203-219). Hay un dato arqueológico, una necrópolis en el río Viern, Vilanova de Prades, que comentaremos posteriormente, $y$ los restos de una torre altomedieval y hábitat asociado en Castellfollit, cerca de Poblet (CARRERAS 1981 pp. 65-99). 
La llegada de las huestes de Tariq desde Zaragoza parece que afectaría fuertemente a las tierras de la Conca, si seguimos la idea de Benet (1995, pp. $431-434$ y 444-445). Aunque en la siguiente oleada la comarca quedó en una zona marginal de las grandes vías de entrada musulmanas.

\section{LA CONQUISTA FEUDAL}

El norte de la Conca de Barberá en el siglo $X$ formaría parte de la llamada frontera del río Gaià, marca condal enfrente de los dominios musulmanes centralizados en Tortosa y Lleida, con un límite septentrional en las montañas de Prades y Montsant. En esta época, en la marca se documenta la existencia de fortificaciones y población, anterior incluso a las primeras referencias escritas (VIRGILI 199I).

La conquista feudal de la Conca fue tarea larga y dura, sacudida por las incursiones islámicas (ESPAÑOL 1991, pp. 17 y ss). El inicio de la explotación agrícola sistemática seria una tarea básica, acompañado ello del nacimiento de pequeños núcleos al pie de castillos, e incastellamenti.

En tiempos de Guifré el Pelós se conquista el castillo de Queralt. En 94I-942 el conde Sunyer conquista Tarragona y los castillos cercanos y la Conca pasan directamente al dominio condal. Pero los musulmanes consiguieron, sin uso de la fuerza, que los feudales desocuparan buena parte del Camp de Tarragona, aunque permanecieron en la Conca.

En 978 la incursión de Al-Mansur afectó la Conca, con la destrucción de los castillos de Al-Daliya (Lilla), Cabra, Selmella. En 980 Borrell Il donaba el castillo de Cabra a Ervigio, en las puertas de la Conca, marcando un hito hacia la expansión en la Catalunya Nova. Años después, en el 1054 se cedía Barberà a Arnau
Pere, ya en el centro de la comarca (ESPAÑOL 1991, pp. 27-51).

Desgraciadamente la incursión de 1033 afectó seriamente la colonización feudal, de manera que se vió documentalmente interrumpida durante unos veinte años, y a partir de mediados del siglo $\mathrm{XI}$ constan donaciones de tierras a aprisiadores. En este momento Ramon Berenguer I se decantó por una política de pactos con los taifas que favoreció la colonización de la comarca, surgiendo cuadras y nuevos castillos. Pero a inicios del XII, las inscursiones almorávides volvieron a sacudir la comarca. A pesar de ello, en este siglo se culmina la conquista feudal. La restauración definitiva de la sede de Tarragona, y las conquistas de Tortosa y Lleida son el canto del cisne del Islam en Cataluña.

La comarca ha sido, pues, interpretada como una zona de frontera, desierta y desolada tras la invasión musulmana y que poco a poco se fue "reconquistando" y "repoblando" por iniciativas personales -aprisiones- $y$ especialmente condales.

Salrach, al estudiar el tema, afirma que la documentación eclesiástica sobre "repoblación" está mediatizada por su propio carácter y se ha leido desde una óptica de "reconquista". Consecuentemente la idea de desierto y despoblación es más bien fruto de una interpretación tendenciosa de los textos, y se inclina a creer en un cierto poblamiento anterior a la conquista y colonización feudales ${ }^{3}$. Barceló, en un estudio sobre la información documental escrita del feudalismo sentencia: "La inmensa mayoría de documentos altomedievales tiene por objetivo fijar relaciones de dominio: son expresiones de poder. Es científicamente adecuado, pues, dudar de la inocencia informativa de los redactores" (BARCELÓ 1989b, pp. 73-87).

El concepto de desierto, tan mencionado en la documentación de la época, se ha interpretado apocalípticamente cuando más bien su

\footnotetext{
3 "No és que el fenomen no hagi existit, (se refeiere a la colonización del llano) i no sigui important, sinó que es basa en documents susceptibles de ser pensats d'una altra manera: documents que, per la seva funció, parlen del que es crea i no del que preexisteix; documents que s'han d'interpretar més com a testimoni d'emigracions colonitzadores que no de creixement de poblacions més sedentaritzades; documents, en fi, que, potser una mica apriorísticament, s'han llegit amb mentalitat de reconquesta, és a dir amb la idea de pensar que tota creació ve de fora" (SALRACH I99I pp. 203-2II).
} 
significado, como bien indica Sabaté, es otro; equivale más bien a la denominación de zonas sin cultivar (SABATÉ 1996 pp.18-31), que obviamente no implica la inexistencia de población.

Ya hemos mencionado la existencia de población en cuevas en determinadas zonas de Cataluña. Al respecto, existe una tradición eremítica de la zona de la Brufaganya, en el norte de la comarca, quizás anterior a la conquista feudal (BOLÒs 1995, pp. 522-523) y que puede ser la legendarización de la existencia de gentes habitando la zona.

Estos datos apuntan a una clara realidad: la iniciativa oficial, condal o eclesiástica ha querido ver, para autojustificarse, que las tierras de conquista y colonización no estaban pobladas, y en el caso de serlo, lo eran por musulmanes o infieles, que no es otra cosa que un eufemismo o el calificativo que recibe la población existente (SABATÉ 1996 pp. |8-31). Hemos de recordar las menciones de la "mala gente" que, como comenta Iglésies (1963, pp. 10-II), vivía hasta la conquista en zonas fuera de jurisdicción feudal, tema que también aborda Bonnassie (1979-8I, vol. I, p.l I0). Estas malas gentes mencionadas en algunos textos, estos personajes que algunos autores han disfrazado de pioneros son realmente una población que quizás nunca abandonó el país.

\section{LAS NECRÓPOLIS DE LOSAS, ¿EVI- DENCIAS ARQUEOLÓGICAS ALTO- MEDIEVALES?}

Posiblemente la negación arqueológica de la despoblación es la existencia de necrópolis. En las comarcas de Tarragona hay un importante conjunto de enterramientos con no pocos problemas a la hora de ser datados y explicados históricamente según la visión tradicional.

Se trataría de agrupaciones rurales más o menos amplias de tumbas de losas, aunque tenemos algún caso, en la comarca del Priorat, de tumbas excavadas en la roca. Aparente- mente no tienen relación con edificios religiosos, y se hallan en el campo, en un punto alto, cerca de una cañada, una fuente o vía de agua.

Por desgracia la mayoría de los datos procede de hallazgos fortuitos o excavaciones antiguas, con una información muy desigual entre las estaciones, muchas de ellas dadas a conocer por Vilaseca y Prunera (VILASECA, PRUNERA 1966 pp. 25-46). Muchas veces son anotaciones, noticias, con problemas de localización, descripción, registro y cronología.

Normalmente son tumbas de losas, de planta rectangular o trapezoidal y cubierta plana, o fosas cubiertas con lajas. Se hallan en agrupaciones orientadas Oeste-Este y con cabecera a poniente, otras Suroeste-Noreste y las menos Sur-Norte. Los restos humanos se hallan en decúbito supino. Casi nunca aparece depósito funerario, de manera que se hace difícil datarlas.

El principal problema que se nos presenta es la cronología. Los enterramientos de losas y fosas simples presentan una larga continuidad desde época tardorromana a medieval ${ }^{4}$, y no ofrecen elementos que nos permitan una datación basada en la tipología, como sucede -aunque se discute- en el mundo de los excavados en la roca.

Por otra parte, su localización, generalmente en puntos aparentemente aislados, sin relación visible con hábitat o lugares de culto, agrava el problema, dado que no hay posibilidad de establecer cronologías relativas basadas en estratigrafías.

\section{I. Albió: tumba del Tossal}

En 1947 se documentó una tumba de losas orientada Noreste-Suroeste, formada por piezas de piedra de más de seis palmos de largo. Según Vilaseca y Prunera se hallaba a unos 300 m. al este del pueblo de Albió, en la falda meridional del llamado Tossal, en castellano montículo (VILASECA, PRUNERA 1966 pp. 25-46). 4 El Dr. Riu al respecto es claro: "Se han efectuado en Cataluña muchos hallazgos esporádicos de cistas, de fecha insegura, dada la exten-
sa perduración del tipo" (RIU 1963 pp. 26I-280). 


\subsection{Albió: necròpolis del Bosque de la Devesa}

En la orilla izquierda del río Corb. Parece ser que se descubrió una necrópolis de tumbas de losas (VILASECA, PRUNERA 1966 pp. 25-46).

\section{3. Albió: tumba del monte de la Devesa}

Vilaseca y Prunera informan que en 1947 se halló una tumba cerca del camino entre Albió y Savellá, a I km. a la izquierda del río Corb, en el monte de la Devesa. Era una cista de losas muy delgadas de unos cinco palmos de longitud (VILASECA, PRUNERA 1966 pp. 25-46).

\subsection{Aguiló: necrópolis cercana a la Cruz de Barràs}

En una excursión de principios de 1897, al lado de la de la Creu (cruz) de Barràs, entre Aguiló y Santa Coloma se observaron varias sepulturas de losas: "Una sola de los quatre allí examinades se conservava ben entera, faltantli sols les lloses que servirían de tapa. Me cridà la atenció lo extraordinari gruix de la closca del cráni, que s'aproximaría á un centímetre; com també lo extraordinari macís dels óssos majors com fémur y tibia, que no dexavan sino un estret lloch pel moll, essent tan macís l'os que mes qu'una canya, semblava una branca de sauquer" (SEGURA 1897).

\subsection{Belltall: necrópolis del Comestany}

A principios de siglo, el sacerdote Miquel Piera publicó la noticia del hallazgo de una serie de tumbas en la partida del Comestany: tres sepulturas, dos pertenecientes a un adulto, $y$ una infantil (PIERA 1904; VILASECA, PRUNERA 1966 pp. 25-46).

\subsection{Conesa: necrópolis de las Comes}

Vilaseca y Prunera localizan enterramientos a uns $2 \mathrm{~km}$. al Noroeste de la partida de las Comes, en la falda de una loma; se excavaron tres tumbas, en dos se conservaban dos esqueletos en decúbito supino, un adulto y un infante. Las cistas tenian una forma trapezoidal y estaban cubiertas por grandes losas de calcárea margosa (VILASECA, PRUNERA 1966 pp. 25-46).

\subsection{Forés: necròpolis del Coll de Ballestar}

Documentada por Mn. Alfons Boqué (1962) y citada por Vilaseca y Prunera. Se trata de seis o siete cistas al lado del camino entre Forés y Belltall, cerca del collado de Ballestar. Orientadas al Este (VILASECA, PRUNERA 1966 pp. 25-46).

\subsection{Forés: necrópolis de Tuells o de los Masos de Forés}

Esta necrópolis se halla en una pequeña loma a 5,5 km. de Sarral y 3,5 de Forés, en dirección Solivella. Se conoce desde los años cincuenta y ha sido objeto de diferentes actuaciones arqueológicas.

En la primavera de 1974, Márius Ferrer delimitó cinco tumbas, habiendo excavado dos de ellas (BATISTA, FERRER 1993 pp. 100-107). Poco después miembros de los Equips de Recerques Arqueològiques de la Reial Societat Arqueològica Tarraconense excavaron las dos restantes (GRAS, RIBAS 1978, pp. I36-14I). Las tumbas estaban orientadas Noroeste-sureste con la cabecera al Noroeste, eran de planta rectangular y se abrían directamente en el terreno. Estaban formadas por una losa en la cabecera y pies y unas cuatro laterales; la cubierta era de losas de arenisca. Los esqueletos se hallaban en decúbito supino.

En la primavera de 1989 el Servei d'Arqueologia de la Generalitat de Catalunya realizó una nueva intervención excavándose veintitrés enterramientos, y descubriéndose más. La mayoría había perdido la cubierta por las labores agrícolas. Destaca la orientación, con una derivación entre los 290 y $300^{\circ}$ Norte, difícil de explicar al no corresponder a la de la salida del sol, y algunas orientadas $305^{\circ}$ quizás por adaptarse al terreno o una racionalización de la necrópolis siguiendo la orientación de un primer grupo de tumbas (FARRÉ 1990 pp. 26-28.).

No se documentaron señalizaciones -estelas- ni reutilización de tumbas. Los esqueletos se depositaron en decúbito supino con los brazos en los lados del cuerpo y manos sobre la pelvis. No se halló ningún ajuar o depósito funerario. 


\subsection{Passanant: necrópolis de las Roques de Dugo}

Joan Duch localizó diversas cistas que toma como tardorromanas, aunque posiblemente sean medievales (ADSERIAS et alii 1989a).

\section{I0. Passanant: necrópolis de los Vilars}

Localizada en la partida del mismo nombre (VILASECA, PRUNERA 1966 pp. 25-46). Se reconocieron varias cistas y posteriormente Joan Duch estudió una tumba de fosa con cubierta de losas dentro de la cual había una jarra de cerámica, tomándose como tardorromana (ADSERIAS et alii 1989a). Hemos de hacer mención del hallazgo de cerámicas romanas en los alrededores.

\section{I I. Passanant: necrópolis de la Partida del Diumenge}

En 1942 se descubrieron cinco o seis cistas orientadas Norte-Sur (VILASECA, PRUNERA 1966 pp. 25-46).

\subsection{Pontils: necrópolis del Mas Marí.}

Entre Pontils y Vallfogona, en 1946, Vilaseca y Prunera recogen la noticia del hallazgo de tres cistas orientadas Este-Oeste (VILASECA, PRUNERA 1966 pp. 25-46).

\subsection{Segura: tumba del coll de Sadern}

Tan sólo tenemos la referencia de Mn. Piera, de la localización de una tumba (PIERA 1904; VILASECA, PRUNERA 1966 pp. 25-46).

\section{I4. Sant Gallard: necrópolis de I'Era del Carraca}

En Sant Gallard, cerca del antiguo camino entre Pontils y Santa Coloma de Queralt, dos o tres cistas medievales orientadas Este-Oeste (VILASECA, PRUNERA 1966 pp. 25-46).

\subsection{Santa Coloma de Queralt: necrópolis del Gubiá, calle del Orfeó Catalá}

Enterramientos descubiertos durante unas obras de alcantarillado, lo que motivó una intervención por parte del Servei d'Arqueo- logia de la Generalitat de Catalunya (PALAU RAFECAS 1988, pp. 12-13).

Se localizaron siete sepulturas alineadas en dirección Norte-Sur, habiéndose documentado al menos restos de ocho individuos enterrados en decúbito supino. Se trataba de fosas, algunas cubiertas por losas. Al no relacionarse con ninguna iglesia, se las supuso pertenecientes a la maqbara de la aljama hebrea de Santa Coloma, documentada entre los siglos XI y XIV (GENERA 1990 pp. 229-230; GENERA et alii 1992 pp. 35-5 I; LEUSSER 1988 p. 129; Catalunya restaura 1991), aunque esta idea es muy difícil de confirmar (cfr. PÉREZ 1978 pp. 333-355; ROMANO 1970, pp. 50-65, 1993-94 pp. 291-315).

\subsection{Vallclara}

Tenemos constancia de la localización de diferentes cistas (VILASECA, PRUNERA 1966 pp. 25-46).

\section{I7. Vallfogona de Riucorb}

Vilaseca y Prunera, en base a Mn. Piera, mencionan la noticia del hallazgo de cistas en diferentes puntos del municipio: la Font Segura, las Fonolloses, el Fonoll, el Forn de Calç, Pla de la Torre, Pla del Pou, Hort del Clos del Rector d'Albió, Planeta de l'Om, Sort del Bató, las Cadenes, Sant Pere dels Bigats (sic), camí de Santa Coloma, Coll de la Bresca, rio Seniol (PIERA 1904).

En el Coll (collado) de la Bresca y el Cap del Pla se hallaron bastantes enterramientos. En el Pla de la Torre estaban orientadas con cabecera a poniente y pies a oriente. La necrópolis de las Cadenes, entre los rios Seniol y Corb, estaba formada por tres agrupaciones de extensión considerable. Mn. Piera dice que "és tot plè de sepultures de la mateixa classe; formen com tres fossars de més de cent passes cada u; es descobriren en obrir rases" (VILASECA, PRUNERA 1966 pp. 25-46).

\section{I8. Vilanova de Prades: maqbara en el río Viern (Francolí)}

A principios de siglo Antoni Llaveria (1917) detectó una serie de tumbas medievales al lado 
del río Viern o Francolí, en la falda de un monte. Parece que se trataba de tumbas de losas, en una de las cuales se halló un esqueleto in situ, en decúbito lateral mirando al Sur, con las piernas un poco encogidas. "No estaba el esqueleto tendido a la larga, sino acostado sobre el lado derecho, mirando al mediodía, y con las piernas hacia atrás. Los cráneos tienen una configuración soberbia" (VILASECA, PRUNERA 1966 pp. 25-46).

La disposición del cadáver, y el sistema de inhumación en cista -que no es ajeno al mundo islámico peninsular- hacen pensar que la necrópolis es musulmana (NAVARRO 1985 pp. 40-45; RIU 1977 pp. 375-490; ROSSELLÓ 1989 pp. I5 - | 68).

\subsection{Vilanova de Prades, necrópolis de la Nou, l'Anové o Anoué}

En 1974, Antoni Arbós recoge la noticia de la existencia de tumbas de "moros": cistas de losas que también se conocen en otros puntos del lugar. (ARBÓS 1983 pp. 45-59, LLAVERIA 1917 pp. 32-35)

\subsection{Vimbodí: tumba de la Granja Mitjana}

En este conjunto romano y medieval, Mn. Bergadá localiza una tumba de bañera (BERGADÀ 1978 p. 30).

\subsection{Vimbodí: necrópolis del Mas de la Cova}

Al pie de un curso de agua, Vilaseca y Prunera mencionan el hallazgo de parte de una cista de losas orientada este-Oeste y a unos metros, otra infantil (VILASECA, PRUNERA 1966 pp. 25-46).

\subsection{Vimbodí: necrópolis de Riudabella}

En esta granja cisterciense, con un precedente romano, se hallaron dos tumbas de bañera (BERGADÀ 1978, p. 30).

\subsection{Vimbodí: necrópolis del Tossal de les Forques o de Nerola}

El Tossal de les Forques es un pequeño promontorio cercano a la carretera Poblet-Prades, y al lado de la fuente de Nerola. En 197I miembros del Grup d'Investigació Espeleològica de Montblanc documentaron dos tumbas de cista. Una ya había sido excavada anteriormente por Salvador Vilaseca y la otra había sido expoliada. En 1983 el Servei d'Arqueologia de la Generalitat realizó una excavación de urgencia (ADSERIAS et alii 1989b pp. 135- 149).

Los dos enterramientos mencionados se forman por una fosa dentro de la cual se colocaron las correspondientes lajas trabadas con piedras. La cubierta era también de piedras. La orientación es Este-Oeste y no se hallaron restos de ajuar ni depósito funerario.

Los restos humanos, aunque removidos, pertenecen a dos individuos femeninos, un adulto grácil y un maduro o senil robusto. Hay también el peroné de un tercer individuo. Ambos esqueletos muestran signos de artrosis y problemas dentarios. En el esqueleto adulto se ha observado un período de carestía entre los dos y tres años, siete maternidades e indicios de una fuerte actividad física. Una osificación inususal en la cavidad cotiloidea en los dos cráneos hace pensar en un parentesco entre ambos esqueletos (VIVES 1989 pp. 135-149; 1990, pp. 78-79).

Además de estas necrópolis tenemos datos de la localización de otros conjuntos funerarios: Lilla, Vimbodí (cerca de la autopista), Espluga de Francolí (Coll d'en Ségol, Pedrols), El Fonoll, Saladern, La Cirera, Montargull, Riudeboix, Vallfogona (La Torre), Albió (camino a Savallá).

\section{PROBLEMAS CRONOLÓGICOS}

Realmente la adscripción cronológica y cultural de las tumbas y necrópolis que hemos comentado es problemática. La falta de elementos que nos permitan dar una cronología absoluta (depósito funerario) o relativa (situación al lado de un edificio, hábitat...) obliga a datarlas en base a paralelismos, tipología o la especulación en el más amplio sentido de la palabra.

\footnotetext{
5 Información facilitada por el museo de Montblanc. Muchas de estas referencias son de Ramon Vidal y Salvador Palau Rafecas.
} 
El primer dilema es diferenciar si son prehistóricas como se ha propuesto en algunos casos. A veces la aparición de material arqueológico de este período -ignoramos si en posición primaria o reutilizado- ha sido elemento suficiente para datar las tumbas, como sería el caso del Mas del Tancat en la comarca vecina del Priorat (DUPRÉ, VILARDELL 1985, pp. I-4), que se ha tomado como una perduración de la cultura de los "sepulcros de fosa" neolíticos.

Al respecto, Batista y Ferrer hacen referencia a las diferencias entre las cistas neolíticas y las medievales: las primeras son más profundas, cerradas por los cuatro lados con gruesas losas de piedra, de planta cuadrangular o ligeramente rectangular similares a la forma ovalada o poligonal, y cubiertas por una gran losa y a veces un túmulo de piedras. El cadáver se colocaba encogido en dirección Este-Oeste o Norte-Sur 6 .

Vistas estas diferencias, hay que establecer si son romanas, tardorromanas o medievales. El mundo funerario tardorromano tiene en la ciudad de Tarragona uno de los más importantes exponentes arqueológicos, la llamada Necrópolis Paleocristiana o Necrópolis de Tabacalera.

Ésta es una amplia zona, o mejor dicho, zonas con espacios funerarios desde época romana republicana, aunque la más interesante para nosotros es la bajoimperial y tardoantigua, datable a partir del siglo III dC.; $y$ en especial las tumbas y enterramientos relacionados con la basilica cristiana donde se enterraron el obispo Fructuoso y sus diáconos Augurio y Eulogio. Las excavaciones realizadas en los años veinte y treinta permitieron establecer una evolución cronotipológica de los tipos de enterramiento.

La posterior revisión efectuada por Del Amo (AMO 1978, p. 93; cfr. TED'A 1987, pp. 188-189) establece una secuencia de aparición de enterramientos: fosa con tegulae horizontales en la cubierta, ataudes de madera, fosa con tegulae a doble vertiente, fosas y ataudes de plomo, sepulturas de tegulae a doble vertiente, fragmentos de ánfora, sepulturas en ánfora, sepulcros de muretes, sepulcros de sección cuadrangular, sarcófagos y finalmente sepulcros de losas.

La excavación de la basílica visigoda del anfiteatro de Tarraco (TED'A 1990), ofreció una serie de enterramientos datados a partir del siglo VI, tipológicamente asimilables a las sepulturas de losas.

Así pues, en época tardorromana y en la antigüedad tardía, hay una utilización de sepulcros de lajas. Esta constatación viene refrendada por la excavación de estaciones en diferentes puntos de la península, donde también se detectan enterramientos del tipo bañera datados en época visigoda, e incluso alguno antropomorfo. Serían los casos de Sant Julià de Ramis, Girona (AGUSTí et alii 1993 pp. 117-128) o La Guardia, Jaén (RIU 1977, p. 420).

En Eucata (Alt Urgell), se localizó una importante necrópolis ${ }^{7}$ : tumbas de tegulae planas o placas de pizarra de sección triangular, cistas de paredes irregulares y cubierta de losas grandes. En este contexto, con tumbas de cista tenemos los casos de Segóbriga (ALMAGRO 1975), O Noviercas, Soria, recientemente publicado por Doménech (1991 pp. 173-182), y que quizás puede ser medieval, como insinúa De la Casa (1992, pp. 354-362).

Tenemos suficientes elementos para afirmar el uso de sepulcros de losas en el mencionado período, sea alrededor de templos cristianos en el mundo urbano, como los enterramientos ad sanctos de las necrópolis de Tabacalera y del anfiteatro de Tarragona, o en agrupaciones más o menos extensas, sin saber si cercanos a un templo o edificio religioso, en el ager.

En cuanto a la adscripción cultural de las tumbas visigodas cabe pensar si se trataría de hispanorromanos, hispanovisigodos o germánicos.

6 Batista y Ferrer (1993 pp. 100-107) basan la diferencia entre las cistas neolíticas y medievals en: RIPOLL, LLONGUERAS 1963 p. 90. Vid. también MUÑOZ 1965. Sobre el neolítico en la Conca, MIRÓ et alii 1995 pp. 65-92.

7 Estudiada por Díez Coronel y mencionada en RIU 1977. 
Hemos de tener en cuenta que los contingentes visigodos llegados a Hispania son mucho menores que la población hispanorromana preexistente (RIPOLL, VELÁZQUEZ 1995, pp. 76-10I), de manera que el impacto demográfico sería muy suave y se hace difícil ver, si realmente existen diferencias (VIVES 1991, pp. 169-170). Además, la arqueología funeraria visigoda en Cataluña nos ha proporcionado unos escasísimos ajuares, a diferencia de Castilla, hecho que para el Dr. Riu sería un indicador de la diferencia entre arrianos visigodos y católicos romanos (RIU 1982 pp. 29-57).

Otro problema que hemos de plantearnos es la relación entre cistas y tumbas excavadas en la roca. En 1962 Alberto del Castillo estableció la cronología de las tumbas llamadas «Olerdolanas» (CASTILLO 1968 pp. 835-845) fijándose de forma definitiva la datación medieval de estos loculi. Esta cronología estaba basada en los resultados de sus excavaciones en Castilla y Cataluña. A partir de entonces, especialmente de la mano del profesor del Castillo y de Manuel Riu se empezó a establecer una secuencia teórica de los tipos de enterramiento: en época tardorromana y visigoda, tumbas de losas, además de las de tegulae y otros tipos menos frecuentes; en el período altomedieval, excavadas en la roca, y partir del siglo XI se data la reaparición de tumbas de losas (RIU 1977 pp. 375-490, 1982 pp. 29-57, 1989 pp. I 17-125). En otras palabras, la secuencia temporal sería groso modo tumbas de losas - tumbas excavadas en la roca - tumbas de losas.

Esta evolución tipológica se ha visto refrendada en bastantes excavaciones de Cataluña y Castilla. Se observa como las primeras fases de diversas necrópolis medievales contienen enterramientos excavados en la roca y los niveles posteriores son de cistas, a veces con una fase intermedia de tumbas de tipo mixto. Serían los casos de Santa Creu del Joglar (PADILLA 1982 pp. 155-176), la Esquerda (OLLICH 1982 pp. 105-147), Sant Vicenç d'Enclar en Andorra (LLOVERA, et alii 1988 pp. 165-176), San Juan de los Caballeros o San Millán de Segovia (ZAMORA 1979a pp. 581606, 1979 b pp. 523-542).

Si aceptamos al pie de la letra esta hipótesis, hemos de datar las tumbas de la Conca de Barberà entre los siglos XI y XIl. Sin embargo, hemos de hacer algunos comentarios.

En primer lugar, si bien es cierta esta secuencia relativa, cista de losas-tumba excavada a la roca-cista de losas, la cronología absoluta es más elástica (cfr. QUIROGA, LOVELLE 1992 pp. 139156). Así en necrópolis visigodas ya se documentan enterramientos antropomorfos en roca, normalmente tomados como altomedievales, caso de La Cabeza, Madrid (YÁÑEZ.et alii 1994 pp. 259-287). En otros casos la datación de las tumbas excavadas en la roca es más tardía, como las de Sant Martí de Lleida (GALLARTet alii 1991), Bellver d'Ossó (RAFEL 1989 pp. 17I-180) o Escornalbou (MENCHON 1995 pp. 21 I-227), que se relacionan con templos románicos del siglo XII.

Al respecto, Rafel apunta la posibilidad que este comportamiento funerario de las tierras leridanas, y por extensión, el de las comarcas tarraconenses dado el caso de Escornalbou, sea más cercano al documentado en Aragón que al de la Catalunya Vella. No sería una relación geográfica, sino temporal: responde a unas necrópolis posteriores a las que conocemos en el norte de Cataluña.

Hay otro aspecto que no se puede pasar por alto, nos referimos a necrópolis altomedievales donde no se han localizado enterramientos en la roca, pero sí una secuencia de cistas, cronológicamente coetáneas al desarrollo de las tumbas llamadas olerdolanas, y además, en muchos casos sin relación alguna con edificios religiosos. El Dr. Riu en su momento ya manifestaba la laxitud cronológica de las tumbas de losas, con un resurgimiento a partir del siglo $X$ y en especial del $X I^{8}$.

8 Riu establece que entre los siglos VIII-IX se localizan fosas mixtas, con una parte de losas y otra abierta en la roca. A partir del siglo $X$ se localizan fosas con paredes de piedra y también "resurgen entonces las sepulturas de lajas de pizarra o de caliza, formando cajas o cistas, en general de planta rectangular y con las paredes formadas por losas puestas verticales, que predominarían a lo largo del siglo XI y penetrarán incluso en el XII" y entre el último tercio del siglo XI y primero del XII "existen también sepulturas de la de sección triangular" imitando las bajorromanas de tegulae e imbrices" (RIU 1977, p. 456). 
La excavación del cementerio del monasterio de Sant Sebastià del Sull (Saldes, el Berguedá) proporcionó un amplio conjunto de tumbas, ninguna de ellas excavada en la roca, y que el Prof. Riu data entre los siglos $X$ y XII (RIU 1982 pp. 29-57). Otros casos de cistas altomedievales son las del Collet de de Sant Pere Mártir, Anoia (ENRICH, ENRICH 1974 pp. 7I-75), Vilasar de Dalt (BATISTA, BONAMUSA 1976 pp. 106-108) y Tordera (BONAMUSA 1977 pp. 4I-42), la Miranda, en el Penedés (BOSCH, VALLĖS 1989 pp. 99-1 14), O en las comarcas del Maresme y Bages, como recopila Sales (1993-94, pp. 317-336). En la Península tenemos casos como Vegas de Pedraza, que se llevan al siglo IX (IZQUIERDO 1975 pp. 1241-1250). En Valeria se datan hasta el siglo XV (FERNÁNDEZ 1981) y en Vila dos Sinos (Portugal) están fechadas entre los siglos VIII y XIII (LEMOS, MARCOS 1985 pp. 127- I46).

En Andorra se observa un hecho similar. Mientras en Santa Eulalia d'Encamp se localizan cistas de pizarra anteriores al siglo IX, y a relacionar con un templo prerrománico, en Sant Vicenç d'Enclar (s.VI-VIII) se documentan cistas, sepulturas antropomorfas en la roca y combinación de ambas. La explicación de la diferencia no se puede, pues, basar en criterios tipológicos, sino en la topografía y geología de cada lugar, que permitiría o no el uso de un determinado tipo de tumba (DD.AA. 1989, pp. 45-48 y I 17-122; LLOVERA et alii 1988 pp. 165- 176). En el Maresme (Barcelona), Clariana observa la existencia de tumbas en la la roca, que data entre los siglos $I X$ y $X$, mientras que las cistas de losas serían de los siglos $X, X I$ y principio del XII (CLARIANA 1992 pp. 493-499).

Hemos de tener en cuenta otro aspecto: la relación entre las necrópolis y los edificios de tipo religioso, que muchas veces es la única manera de poder datar las primeras: la relación estratigráfica entre las tumbas y la estructura de los templos. Pero ¿qué sucede con los agrupamientos funerarios de la zona tratada, donde no se ha establecido relación alguna con edificios religiosos?
Sabemos que estos cementerios son conjuntos más o menos amplios de tumbas, aunque no conocemos ninguno de forma total, pese a que probablemente nos hallemos con algunas agrupaciones bastante importantes. Muchas se hallan, insistimos, en lugares altos, elevaciones, faldas de montes, cerca de un camino o cañada, o de un curso de agua o fuente. No tenemos datos que permitan relacionarlas con edificios religiosos o hábitat inmediatos. Tampoco conocemos en la Conca de Barberà la existencia de tumbas en la roca.

Bosch y Vallés (1988, pp. 327-338) estudiaron la relación de las necrópolis de cistas y/o tegulae con los contextos inmediatos. Relacionaban las tumbas con villas romanas como elemento de continuidad de población ya cristiana en la antigüedad tardía, con la intención de reutilizar materiales constructivos, como también las localizadas en poblados ibéricos (sic). Las tumbas en montes y montículos aislados serían las correspondientes a un hábitat rural disperso, con mezcolanza de tradiciones cristianas e indígenas, datándose entre los siglos $V$ y VII, aunque también puedan corresponder al inicio del movimiento colonizador del llano (s. IX-X). Las necrópolis en el llano se relacionan con un hábitat disperso y la cristianización de las zonas más romanizadas?.

Así pues, hoy por hoy se hace difícil datar estas tumbas de forma precisa. Pese a todo cabe hacer algunas consideraciones para poder acercarnos a su adscripción temporal:

I. Relación de los enterramientos con yacimientos de época romana y visigoda, que nos indica una continuidad de población durante la baja romanidad y antigüedad tardía y posiblemente después.

2. La situación de buena parte de estas necrópolis en la zona montañosa de las comarcas tarraconenses: Miramar, Mussara, Montsant, Montmell, el Tallat, Brufagaña, montañas de Prades, la Llena, puede ser indicador de

\footnotetext{
9 Estas relaciones y cronologías no están tan claras com proponían Bosch y Vallès..
} 
la ruralización del territorio, o mejor el "abandono" del llano, quizás a partir de la antigüedad tardía y también, claro está, entre el 7I3-I4 y la conquista feudal.

3. La situación de las necrópolis en lugares altos, elevaciones, faldas de montes, cerca de caminos o cursos de agua indica, al menos aparentemente, la falta de relación de los conjuntos con edificios religiosos, y de una independencia de los grupos usuarios de las tumbas con la institución eclesiástica, por tanto, feudal.

4. Ello lleva a plantear el carácter cristiano, semipagano o la continuación de ciertas tradiciones religiosas, mágicas o formales de tipo precristiano.

5. La posibilidad de que estas tumbas ocupen el amplio -demasiado- abanico cronológico entre la baja romanidad y la conquista feudal es un elemento que apunta directamente a la continuidad, o al menos, a la perduración de hábitat en este período oscuro.

Como indica Sales, el problema de estas necrópolis es datarlas antes o después de la invasión musulmana (7|3-7|4). En el primer caso nos muestran la ruralización del mundo romano y visigodo, y en el segundo, la perduración o continuidad del hábitat en la alta edad media en unas zonas tradicionalmente tomadas como despobladas (SALES 1993-94, pp. 317-336). Se hace también necesario apuntar la posibilidad de si estas necrópolis puedan pertenecer también a grupos foráneos, árabes, bereberes.

En el caso de las necrópolis anteriores a la conquista islámica, el primer problema sería diferenciar entre las hispanorromanas e hispanovisigodas, y su carácter cristiano (arrianoromano) y pagano, que como hemos dicho, por la falta de ajuares y otros elementos se hace muy difícil. Sería la explicación de los enterramientos de losas estudiados en la plana de Vic por Ollich y Raurell (1989, pp. 223-250).
Si se trata de conjuntos posteriores al 7/3$7 \mid 4$, se ha de plantear su posible carácter musulmán. En este caso, la posición del decúbito lateral puede ser un buen indicador. En la zona de Lleida (comarcas del Segrià, Garrigues y Pla d'Urgell correspondientes también en parte a la Catalunya Nova) se conoce un buen número de necrópolis, sean cistas, sean excavadas en la roca, recopiladas recientemente, que se deben interpretar como demostración de este continuum de población, sea musulmán, cristiano o pagano (BOLÒS 1997, pp. 93-101).

En este contexto medieval, debemos pensar si se trata de necrópolis anteriores o posteriores a la conquista feudal. Si aceptamos el primer caso, su situación topográfica y la falta de relación aparente con un edificio religioso iglesia- serían argumentos que abundan a favor de la idea: necrópolis pertenecientes a pequeños grupos humanos, quizás descendientes de la población de la antigüedad tardía, que viven en zonas de montaña y que se dedican a la agricultura y ganaderia; quizás cristianos, quizás paganos o con reminiscencias precristianas que se plasman al escoger los lugares de enterramiento. No se puede obviar que se pueda tratar de gentes llegadas tras la conquista islámica, especialmente a partir del año 1000 ... quizás bereberes. En los extrema durii de la conquista feudal castellana, la existencia de enterramientos altomedievales ha desballestado la idea de despoblación anterior de la "reconquista" y repoblación, que su día defendió Sánchez Albornoz. Así, el estudio de las necrópolis, en este caso excavadas en la roca, demuestran esta idea, como sería el caso de la provincia de Soria (CASA 1992 pp. 354-362, 1993 pp. 89-94).

Pensar en una perduración de poblamiento entre la baja romanidad y la conquista feudal es una tentación evidente. Pero no estamos en condiciones de conocer cuál sería su intensidad en aquel período ni tampoco su grado de cristianización, que conllevaría el sepelio en lugares aislados o villas, como defienden Bosch y Vallés (BOSCH, VALLÈS 1988, pp. 327-338) ${ }^{10}$.

10 Los yacimientos de la Conca con evidencias de ocupación romana y medieval, y no afirmamos que en todos haya un continuum: en Barberà de la Conca, Sant Pere d'Embigats, Borrells (con cerámica andalusi?); en Montblanc, Molins de la Vila, con villa romana y el despoblado de Vilasalva; en Passanant: Vilars; en Sarral, Pedrinyà o Pedrenya con villa y despoblado medieval; en Vimbodí: el Codós, con villa y despoblado medieval, Granja Mitjana, Milmanda y Riudabella, las tres granjas cistercienses de Poblet Cfr. ADSERIAS et alii I989a. 
Tampoco es fácilmente aplicable la idea propuesta por estos autores, de relacionar las necrópolis con el fenómeno colonizador de los siglos IX y X, cuando éste es propio de la Catalunya Vella y en época carolingia si seguimos la fuente que nos proponen (SALRACH 1982 pp. 206-232). Pese a todo, la coincidencia de evidencias de una ocupación medieval sobre una romana puede llevar a pensar en la continuidad o pervivencia como defienden Clariana y Prevosti en el Maresme (CLARIANA, PREVOSTI 1988 pp. 429-436), o quizás la reocupación de un lugar apto para vivir.

Recientemente se ha publicado el estudio del yacimiento de Vilaclara de Castellfollit del Boix (Bages). Se excavaron tres grandes espacios abiertos a sendos patios. En cada espacio, un horno de pan, silos, depósitos y estructuras de transformación de productos agrícolas. Es una explotación agrícola con espacios comunales, que se data en el siglo VII, siendo para los excavadores un puente entre las villas romanas y los mansi altomedievales. Cerca había una necrópolis desaparecida hace algunos años.

Este tipo de asentamiento rural sería fruto de la dispersión de los antiguos núcleos tardorromanos en unidades agrícolas menores, con agrupamiento de algunas familias con un sistema de explotación comunal. El fenómeno se enmarca en un contexto de crecimiento de la economía rural, que se realiza entre los siglos VII y VIII (ENRICH et alii 1995 pp. 96-99).

Una serie de estudios polínicos e históricos en el Penedés y Garraf complementan estos hallazgos arqueològicos (ESTEBAN et alii 1993 pp. 647-655). Se detecta que entre los siglos III y VII/VIII una desforestación y actividad agrícola limitada pero diversificada en el llano. Entre los siglos VII y VIII y XII, una gran transformación con desforestaciones mediante el fuego, ganadería extensiva y retracción de la agricultura, tanto en la zona de costa del Garraf y Pene- dés, como en el Besòs, el Pla de Barcelona en el siglo VII o en Ullastret (Girona) en el siglo V. Finalmente, los análisis de $\mathrm{Cl} 4$ de los enterramientos hallados sobre los niveles de abandono de la villa romana de Santa Tecla-la Gravosa (Santa Margarida i els Monjos, el Penedès) han dado una cronología precisa, siglo $X$, lo cual cuadra perfectamente con la propuesta que aquí se presenta (GARCIA et alii en prensa).

Estos elementos nos hacen pensar que la ruptura ocasionada por la conquista islámica no es tan brutal como parecía, aunque tampoco se puede minimizar. A pesar de todo la vida continuó. Quizás este crecimiento de la actividad pecuaria evoca la ubicación de las necrópolis que nos ocupan: en la montaña, cerca de cañadas y caminos, y de cursos de agua. Podría tratarse de comunidades en buena parte dedicadas a la actividad pastoril, como se insinúa en Castilla "'.

Para acabar de complicar la situación nos cabe otra posibilidad, que al menos una parte de las tumbas sea posterior a la conquista feudal. Riu nos dice: "a mig segle XI no s'havia generalitzat l'enterrament de morts familiars als cementiris parroquials, tot $i$ ésser ja plenament cristians (...) I en aquells moments hom fomentava la creació de sagreres, al voltant de les esglésies" (RIU 1982 pp. 29-57). Así es también posible que alguna de estas necrópolis corresponda a los primeros momentos después de la conquista, con un patrón diferente al que después sería la implantación de la red parroquial por parte de los feudales.

La cita puede explicar la existencia de estas necrópolis en zonas conquistadas entre los siglos $X$ y Xl, por ejemplo, en el norte de la Conca de Barberà y Gaià. Pero, ¿qué pasa entonces con las necrópolis en zonas donde el feudalismo se implanta a partir del XII, como el Camp de Tarragona, Priorato o la zona del Ebro?

\footnotetext{
II DE LA CASA 1992, p. 4I7. Dice textualmente: "Los habitantes de esta provincia empezaron siendo comunidades, posiblemente itinerantes, de ganaderos y cazadores, que en plena Edad Media se establecen en núcleos urbanos, entrando a formar parte de un habitat estable o sedentario y pasando a agruparse en las parroquias o «collaciones» de las urbes".
} 


\section{CONSIDERACIONES FINALES}

El problema de las necrópolis en lugares aislados es un tema bastante resbaladizo. Su datación se hace difícil y muchas veces se ha de basar más en la especulación que en la evidencia científica. Es realmente un caso complejo. De todas maneras, es de suponer que la idea de la continuidad de población, o al menos su perduración, se ve reflejada en como mínimo una parte de las necrópolis mencionadas.

Es plausible pensar que las necrópolis relacionadas con villas indiquen la existencia de población por lo menos hasta la conquista islámica, y posiblemente después, como se ha demostrado en el Penedès (GARCíA et alii en prensa).

La localización de grupos de tumbas en zonas de montaña lleva a pensar en la ruralización del territorio, e incluso su abandono para refugiarse en zonas más "seguras" o aptas para la ganadería, a partir de la antigüedad tardía y época altomedieval.

Ello implicaría una cierta continuidad de la población, quizás con incorporación de nuevos grupos humanos (árabes, bereberes), aunque con unas pautas de asentamiento y sistema económico y social diferentes. En cuanto a su carácter cristiano o no, se hace difícil poder decirlo; tan sólo podemos asegurar que se trata de una pauta funeraria muy diferente a la anterior y a la que se implantará con el feudalismo (RIU i BARRERA 1991 pp. 265-272).

En este contexto, hay que profundizar en un tema tan interesante como la construcción de iglesias románicas sobre necrópolis preexistentes, como se observa en la Catalunya Vella, hecho que enlaza con la idea de cristanizar, reconsagrar o controlar religiosa y económicamente espacios funerarios hasta entonces fuera del control feudal de la Iglesia (SERVEI 1983, 1989).

\section{BIBLIOGRAFÍA}

ADSERIAS, M. et alii ( 1984): "El jaciment arqueològic dels Clots Martells (Solivella)". Miscel/lània d'Estudis Solivellencs, 2, pp. 58-60.

ADSERIAS, M. et alii (1989a): Carta Arqueològica. Comarca Conca de Barberà. Barcelona, Direcció General de Patrimoni Cultural, Servei d'Arqueologia.

ADSERIAS, M. et alii (1989b): "Enterraments medievals en el Tossal de les Forques ( Vimbodí, Conca de Barberà)". Aplec de treballs, 9, pp. |35-।49.

AGUSTÍ et alii (1993): "La necròpoli de les Goges (Sant Julià de Ramis, Gironès)". Tribuna d'Arqueologia 1991-92. Barcelona, pp. 117-128.

ALMAGRO, M. (1975): Necrópolis hispano-visigoda de Segobriga, Saelices (Cuenca) "Excavaciones Arqueológicas en España" núm. 84.

AMIGÓ, R. (1989): Sobre inventaris de noms de lloc. Reus.

AMO, D. del (1978): Estudio crítico de la necrópolis paleocristiana de Tarragona. Tarragona.

AMO, D. del (1984): "Bronces de la basílica y cementerio paleocristiano de Tarragona". Butlletí Arqueològic, 16, pp. |67-180.

ARBÓS, A. (1983): "La romanització de la Conca de Barberà. Algunes aportacions". Arrels, 2, "XVIII Assemblea Intercomarcal d'Estudiosos. Setembre 1974", pp. 45-59.

BALAÑ̀̀, P. (1984): "Sobre els mots catalans del tipus «LI-» procedents de l'àrab". Societat d'Onomàstica. Butlletí interior, XVII, pp. 45-5I.

BALAÑ̀̀, P. (1988): "Una metodologia simplificada per a la recerca d'etimologies aràbigues. Aplicació al cas de «Llorac»". Studia in honorem M. de Riquer, Barcelona, "Quaderns Crema", vol. III, pp. II-23.

BALAÑ̀̀, P. (1992): Crònica política de la pre-Catalunya islàmica. Barcelona.

BALAÑ̀̀, P. (1993a): Els musulmans a Catalunya (7/31 153). Assaig de síntesi orientativa. Sabadell.

BALAÑ̀̀, P. (1993b): "Vestigis de la dominació islàmica a la Conca de Barberà, I: la toponímia del municipi de Llorac". Aplec de treballs, II, pp. 203-219.

BARCELÓ, M. (1988): "La invasió àrab-musulmana a Catalunya". L'Avenç, I17, pp. 14- 17.

BARCELÓ, M. (1989a):"Feudalismo e historia medieval" in BARCELÓ et alii 1989, pp. 21-52.

BARCELÓ, M. (1989b): "Los límites de la información documental escrita" in BARCELÓ, et alii 1989, pp. 73-87.

BARCELÓ, M.et alii (1989): Arqueología Medieval. A las afueras del medievalismo. Barcelona. 
BATISTA, R:; BONAMUSA, J. (1976): "Troballa d'una necròpolis de l'Alta Edat Mitjana a Vilassar de Dalt". Información Arqueológica , 16, pp. 106-108.

BATISTA, R.; FERRER, M. ( 1993): "Aportació a l'estudi dels sepulcres de lloses". Empúries, 48-50, vol. II, pp. 100- 107. BENET, A. (1984): "La Conca de Barberà, terme municipal romà?". Miscel/lània d'Estudis Solivellencs, 2, pp. 61-66.

BENET, A. (1995): "La invasió sarraïna". Catalunya Romànica. Barcelona, vol. XXI, "El Tarragonès, el Baix Camp, I'Alt Camp, la Conca de Barberà, el Priorat", pp. 431-434 y $444-445$.

BERGADÀ, A. (1978): Vimbodí. Estudi històric, sociològic i religiós. Vimbodí.

BERGES, M. (1969-70): "Informe sobre "Els Munts"'. Boletín Arqueológico, época. IV, fasc. 105-II2, pp. 140-150.

BOLÒS, J. (1995): "Ermitatges de Sant Martí de la Brufaganya". Catalunya Romànica.. Barcelona, vol. XXI, "El Tarragonès, el Baix Camp, l'Alt Camp, la Conca de Barberà, el Priorat", pp. 522-523.

BOLÒS, J. (1997): "L'arquitectura civil i militar i l'arqueologia". Catalunya Romànica. Barcelona, vol. XXIV, "El Segrià, les Garrigues, el Pla d'Urgell, La Segarra, l'Urgell", pp. 93-101.

Bolòs, J.; Pagès, M. (1982): "Les sepultures excavades a la roca". "Necròpolis i Sepultures Medievals a Catalunya". Acta/Mediævalia anejo I, pp. 59-I03.

BONAMUSA, J. (1977): "Necròpolis de l'Alta Edat Mitjana a Sant Pere de Riu (Tordera)". Quaderns de Prehistòria i Arqueologia de Mataró i el Maresme , 2, pp. 4l-42.

BONASSIE, P. (1979-8I): Catalunya mil anys enrera (segles $X-X I)$. Barcelona, 2 vols.

BOSCH, J.; VALLÈS, J. Ma . (1988): "Sepultures tipus cista de lloses i/o «tegulae» a Catalunya: hipòtesi interpretativa". Actas del II Congreso de Arqueología Medieval Española, vol 3, pp. 327-338.

BOSCH, J.; VALLÈS, J. Ma . (1989): "La Miranda, una necrópolis medieval de turó ailllat del Penedès". Miscel/lània Penedesenca núm XI, "Comunicacions presentades a les I eres. Jornades d'Estudis Penedesencs". pp. 99- I I4.

BÖUARD, M. (1977): Manual de Arqueología Medieval, de la prospección a la Historia. Barcelona.

CARRERAS, A. (198I): "La torre de guaita de Castellfollit (Serra de Prades). Notes arqueològiques i planimetria". Butlletí Arqueològic , 3, pp. 65-99.

CASA, C. de la (1992): Las necrópolis medievales de Soria. Valladolid.

CASA, C. de la (1993): "Despoblación y repoblación de los extrema durii". III Curso de Cultura Medieval. Repoblación y reconquista (Aguilar de Campóo 1991). Aguilar de Campóo, pp. 89-94.
CASTILLO, A. del (1968): "Cronología de las tumbas llamadas «Olerdolanas»". Crónica del XI Congreso Nacional de Arqueología. Zaragoza, pp. 835-845.

Catalunya restaura (1991) Catalunya restaura. Expo-conservació de Béns Culturals. Centre d'Art Santa Mònica. Barcelona.

CLARIANA, F. (1992): "Anotaciones al estudio de las necrópolis altomedievales de la comarca del Maresme". Actas del III Congreso de Arqueología Medieval Española. Oviedo 1989, Tomo II, pp. 493-499.

CLARIANA, F.; PREVOSTI, M. (1988): "Sobre la pervivencia de hábitats rurales romanos en la Alta Edad Media en el Maresme". Actas del II Congreso de Arqueología Medieval Española, (Madrid 1987) vol. III, pp. 429-436.

COLL, J.Ma . et alii (1995): "El fondal de Vandellós (Mediona, Alt Penedès): un nucli eremític-cultual en cova del s. V". Miscel/lània Penedesenca XX-1994, Comunicacions en les 7enes Jornades d'Estudis Penedesencs, Sant Sadurní d'Anoia 3-4-5 de juny de 1994, vol II El Penedès, pp. 169. 183.

CURTO, A. et alii (1984): "Excavacions al castell de la Suda de Tortosa". Sharq al-Andalus. Estudios árabes, I, pp. |4|-| 46.

DD.AA. (1989): Santa Eulàlia d'Encamp. Evolució d'un edifici. Segles IX-XX. Andorra.

DOMÉNECH, M. (|99|): "La necrópolis hispano-visigoda de «Fuente de la torre» Noviercas (Soria)". Soria Arqueológica, I, pp. 173-182.

Duch, J. (1979): "La vall del Corb i les seves estacions prehistòriques". XVII Assemblea Intercomarcal d'Estudiosos. 21 d'octubre de 1973 a Santa Coloma de Queralt. Aplec de les Ponències i Comunicacions. Santa Coloma de Queralt, pp. II7-129.

DUPRÉ, X:; VILARDELL, R. (1985): "El sepulcre del Mas del Tancat (La Morera del Montsant, Priorat". Informació Arqueològica, 44, pp. I-4.

ENRICH, J: ENRICH, J. ( 1974): "Sepulturas medievales del «Collet de Sant Pere Màrtir»". Información Arqueológica, I5, pp. 7|-75.

ENRICH, J. et alii (1995): Vilaclara de Castellfollit del Boix (El Bages). Un assentament rural de l'antiguitat tardana. Igualada.

ESPAÑOL, F. (|99|): L'arquitectura religiosa romànica a la Conca de Barberà i Segarra tarragonina. Montblanc.

ESPELT, J:; POBLET, C. (1978): "Una sivella visigòtica del segle VIlè". Aplec de treballs, I, pp. 25-32.

ESTÉBAN, A: et alii (1993): "Transformacions del paisatge i ramaderia a la costa catalana del Penedès i Garraf (Barcelona) a l'alta edat mitja". IV Congreso de Arqueología Medieval Española. Sociedades en Transición/ IV Congrés d'Arqueologia Medieval Espanyola. Societats en transició. Alacant, octubre de 1993. vol II, "Comunicaciones/ Comunicacions", pp. 647-655. 
FARRÉ, R. (1990): "Les tombes de «Tuells»". El Baluard. Revista d'informació local, 43, pp. 24-25.

FERNÁNDEZ, J.J. (1981): Excavaciones medievales en Valeria. Cuenca.

GALLART, J. et alii (199|): L'excavació de l'església de Sant Martí de Lleida. Lleida.

GARCÍA, J. et alii: (en prensa): "Santa Tecla-La Gravosa: datacions del Carboni 14 de restes humanes (Santa Margarida i els Monjos)". I $0^{\text {enes }}$ Jornades d'Estudis Penedesencs, Santa Margarida i els Monjos 1997.

GENERA, M. (1990): "Sepultures del carrer de l'Orfeó Català. Santa Coloma de Queralt (Conca de Barberà). Campanya: 1988". Butlletí Arqueològic, 12, pp. 229-230.

GENERA, M. et alii (1992): "Aportacions a la història de Santa Coloma de Queralt: dades sobre una necròpolis excavada en el nucli urbà". Recull Mateu Fletxa "El Vell" (| 48 I- | 553). Tarragona, pp. 35-5।.

GORT, E. (1989): "Tarragona i el Tarragonès a l'edat mitjana"; in Història del Camp de Tarragona, I "El Tarragonès". Tarragona, pp. 34-62.

GRASJ.; RIBAS, J. (1978): "Dos sepulturas altomedievales en Forés". Boletín Arqueológico fascs. I4I-I44, pp. I 36-I4I.

IGLÉSIES, J. (1963): La Reconquesta a les valls de l'Anoia i el Gaià. Barcelona.

IZQUIERDO, J. Mª. (1975): "La necrópolis medieval de las Vegas de Pedraza (Segovia)". XIV Congreso Nacional de Arqueología. Vitoria, pp. 124I-1250.

JUAN, J. (1995): "L'aplicació de nous mètodes en la investigació del món de la mort: l'estudi de les restes vegetals". Citerior. Revista d'arqueologia i ciències de l'Antiguitat, I, L'Arqueologia de la Mort. El món funerari a l'antiguitat a la Catalunya Meridional, Tarragona, pp. 203-210.

JUAN, J.: LALUEZA, C. (1994): "Aportacions de les anàlisis fitolitològiques a l'estudi dels patrons de dieta vegetal en poblacions medievals de la Península Ibèrica". IV Congreso de Arqueologia Medieval Española.Vol. II, pp. 687-69l.

LEMOS, F.S.; MARCOS, D. ( 1985): "A Necrópole Medieval de Vila dos Sinos -Mogadouro Segunda Campanha de Escavações-1982". Cadernos de Arqueologia (Portugal), I, pp. 127-| 46.

LEUSSER, D. (1988): "Esquelet humà". Memòria d'activitats del Centre de Conservació i Restauració de Béns Culturals i Mobles de la Generalitat de Catalunya 1982-1988. Barcelona, p. 129.

LLAVERIA, A. (1917): "Al pie de los montes de Prades". Boletín Arqueológico, época II, 14, pp. 32-35.

LLOVERA, X. et alii (1988): "Sant Vicenç d'Enclar". Andorra Romànica, Barcelona, pp. I65-176.

MACIAS, J.M․ et alii (1995): "De arqueologia populetana. A propòsit del suposat visigotisme d' algunes peces del monestir de Poblet". Aplec de Treballs, I3, pp. 93-I03.
MARCET, R. (1983): "Prehistòria del lloc on va néixer l'Espluga el 1079 i les seves rodalies". El Francolí, 3, Abril, pp. 17-18.

MARTÍ, R. (1988): "Tradició i innovació de l'espai agrari medieval". Segones Jornades de Joves Historiadors i Historiadores. Barcelona (preactas fotocopiadas).

MARTÍ, R. (1993): "Quí són els pobladors". Catalunya Romànica, vol XIX, "El Penedes, Anoia". Barcelona, pp. 32-35.

MAYER, M.; POBLET, M. (1992): "Una inscripció romana a Riudabella". Aplec de treballs, 10, pp. 143-150.

MENCHON, J. (1992): "Arqueologia medieval a les comarques tarragonines, estat actual". Acta Arqueològica de Tarragona V (1991-92). Tarragona, pp. 7-30.

MENCHON, J. (1995): "Arqueologia medieval i món funerari a les comarques tarragonines". Citerior. Revista d'arqueologia i ciències de l'Antiguitat, I, "L'Arqueologia de la Mort. El món funerari a l'antiguitat a la Catalunya Meridional". Tarragona, pp. 21 I-227.

MENCHON, J. (1996): Arqueologia funerària medieval a la Conca de Barberà. Estat actual Montblanc.

MENCHON, J.; TOSAS, T. (1995): "Annex I. Necròpolis medievals anteriors al 1300 del Camp de Tarragona, el Priorat i la Conca de Barberà". Catalunya Romànica.. Barcelona, vol. XXI "El Tarragonès, el Baix Camp, l'Alt Camp, la Conca de Barberà, el Priorat". Barcelona, pp. 590-59l.

MIRÓ, J.Ma . et alii ( 1995): "Un enterrament neolític a Vimbodí: la cista del Comellar de Mas de Baix i el neolític a la Conca de Barberà". Aplec de Treballs, 13, pp. 65-92.

MUÑOZ, A. Ma. (1965): La cultura neolítica catalana de los «Sepulcros de fosa». Barcelona.

MUÑOZ, A. et alii: (1995): "Nuevos elementos decorados de arquitectura hispano visigoda en la provincia de Tarragona". Archivo Español de Arqueología, 68, núm. 171172, pp. 293-30।.

NAVARRO, J. (1985): "El despoblado islámico de Siyâsa (Cieza)". Revista de Arqueología, 53, pp. 40-45.

"Noticiari" (1994): "Noticiari". Aplec de Treballs, 12, p. 197.

OLLICH, I. ( 1982): "Tipologia de les tombes de la necròpolis medieval de l'Esquerda (Osona)". "Necròpolis i Sepultures Medievals a Catalunya". Acta/Mediævalia annex I, pp. 105-147.

OLLICH, I.; RAURELL, S. (1989): "Tombes de llosa als turons de la Plana de Vic: una població alt-medieval per cristianitzar?". Acta IMediævalia, I0, pp. 223-250.

PADILLA, I. (1982): "La necròpolis de Santa Creu de Joglars (Osona)". "Necròpolis i Sepultures Medievals a Catalunya". Acta/Mediævalia anejo I, pp. I55-I76.

PADRÓ j. ; VEGA, J. de la (1989): "Treballs arqueològics a la Cova de la Colomera o de les Gralles (Sant Esteve de Sarga -Mur, Pallars Jussà). Excavacions arqueològiques d'urgència a les comarques de Lleida. Barcelona, pp. 9-53. 
PALAU RAFECAS, S. (1988): "Enterraments al poblat ibèric del Gubià". La Segarra año X, 103, Marzo, pp. 12-13.

PERA, J. (1994): "Reflexions entorn el Municipium Sigarrensis". IV Congrés Internacional d'Arqueologia Clàssica. La ciutat en el món romà.I XIV Congreso Internacional de Arqueología clásica. La ciudad en el mundo romano . Tarragona, vol. 2 "Comunicacions", pp. 323-325.

PÉREZ, E. (1978): "Apuntes para el estudio de las necrópolis judías de época medieval o ensayo de tipología sepulcral". Sefarad, XXXXVIII, pp. 333-355.

PERIS, J. et alii ( 1989): "Recerques sobre l'ordenació territorial de la Conca de Barberà en època romana". Aplec de Treballs, 9, pp. |5|-|68.

PIERA, M. (1904): La font prehistòrica i medicinal de Vallfogona de Riucorb. Barcelona.

QUIROGA, L.; LOVELLE, M. (1992): "Propuesta de cronología e interpretación de los enterramientos en piedra de Galicia durante la Alta Edad Media". Boletín de Arqueología Medieval, 6, pp. 139-156.

RAFEL, N. (1989): "Excavacions a l'església de Sant Pere de Bellver d'Ossó (Ossó de Sió, I'Urgell)". Excavacions arqueològiques d'urgència a les comarques de Lleida. Barcelona, pp. $17 \mid-180$

RAURET, A. Ma (1962): "Consideraciones sobre hallazgos ibero-romanos en la Font Major". VII Congreso Nacional de Arqueología, Barcelona 1960, p. 25I.

RECASENS, J. Mª (1975): La ciutat de Tarragona. BarceIona.

REYES, T. (1993): "Del Baix Imperi a l'Alta Edat Mitjana". Catalunya Romànica. vol XV, "El Pallars". Barcelona, p. 24

RIPOLL, E.; LLONGUERAS, M. (1963): "La cultura neolítica de los sepulcros de fosa en Catalunya". Ampurias, núm. XXV, p. 90

RIPOLL, G.; VELÁZQUEZ, I. (1995): La Hispania visigoda. Del rey Ataúlfo a Don Rodirgo. Madrid, Historia 16 "Historia de España" núm 6.

RIU, M. (1963): "Problemas arqueológicos de la transición al mundo medieval. Orientaciones metodológicas". Problemas de la Prehistoria y la Arqueología Catalanas. II Symposium de Prehistoria Peninsular, 8-II de Octubre de 1962. Barcelona, pp. 26|-280.

RIU, M. ( 1977): "La Arqueología Medieval en España". En BÖUARD, Michel de: Manual de Arqueología Medieval. De la prospección a la historia. Barcelona, pp.375-490.

RIU, M. ( 1982): "Alguns costums funeraris de l'Edat Mitjana a Catalunya". "Necròpolis i Sepultures Medievals a Catalunya". Acta/Mediævalia annex I, pp. 29-57.

RIU I BARRERA, E. (1988): "De l'arqueologia i la formació de l'espai feudal". Segones Jornades de Joves Historiadors i historiadores. Barcelona (preactas fotocopiadas).
RIU I BARRERA, E. (|99|): "Temples i espai feudal des de l'Arqueologia". Simposi Actuacions en el patrimoni edificat medieval i modern (segles X al XVIII). Barcelona 5, 6, 7 d'octubre de 1989. Barcelona, "Quaderns Científics i Tècnics" núm. 3, pp. 265-272.

ROMANO, D. (1970): "Cementerios judíos de Lleida". Sefarad , XXX, pp. 50-65.

ROMANO, D. (1993-94): "Fossars jueus catalans". Acta/Mediævalia, |4-15, pp. 29|-315.

ROSSELLÓ, G. (1989): "Almacabras, ritos funerarios y organización social en Al-Andalus". III Congreso de Arqueologia Medieval Española. Oviedo 27 marzo-I abril 1989. Vol. I "Ponencias", pp. |5|-|68.

SABATÉ, F. (1996): L'expansió territorial de Catalunya (segles IX-XII): ¿conquesta o repoblació?. Lleida.

SALES, J. (1993-94): "Tombes i necròpolis isolades a la comarca de I'Anoia". Acta/Mediaevalia, I4-15, pp. 317-336.

SALRACH, J. Ma. (1982): Història dels Països Catalans. Barcelona, vol. I "Dels Orígens a 17|4".

SALRACH, J. Mª. (1991): "Conquesta de l'espai agrari i conflictes per la terra a la Catalunya carolíngia i comtal". Catalunya i França meridional a l'entorn de l'any mil. Actes del colloqui internacional Hug Capet. Barcelona, pp. 203211

SÁNCHEZ, J. et alii (1990): "Una necrópolis musulmana en el Cabezo del Aljezar (Ricote, Murcia)". Actas del II Congreso de Arqueología Medieval Española, (Madrid 1987) vol. III, pp. | 49- 156.

SANS TRAVÉ, J. Ma. ( I995): "Els precedents antics de la prehistòria a la fi del món antic". Catalunya Romànica. Barcelona, vol. XXI "El Tarragonès, el Baix Camp, l'Alt Camp, la Conca de Barberà, El Priorat", pp. 429-43I.

SEGURA, J. (1897): "Revista de la Asociación ArtísticoArqueológica Barcelonesa" núm. 3, Abril-Junio.

SERVEI (1983): Servei de Catalogació i Conservació de Monuments, Memòria 1983, Barcelona.

SERVEI (1989): Servei de Catalogació i Conservació de Monuments, "Recerques històrico-arqueològiques al Bergadà (1983-1986)". Quaderns científics i tècnics I, Barcelona.

SITJES, X. (1994): L'art funerari medieval a la conca del Llobregat.. Manresa.

TED'A (1987): Taller-Escola d'Arqueologia, Els enterraments del Parc de la Ciutat i la problemàtica funerària de Tàrraco. Tarragona.

TED'A (1990): Taller-Escola d'Arqueologia, L'amfiteatre romà de Tarragona, la basílica visigòtica i l'església romànica. Tarragona.

VILASECA, S.; PRUNERA, A. (1966): "Sepulcros de losas, antiguos y alto medievales de las comarcas tarraconenses". Boletín Arqueológico fasc. 93-96, pp. 25-46. 
VIRGILI, A. (1984): "La qüestió de Tarraquna abans de la conquesta catalana". Quaderns d'Història Tarraconense, V, pp. 7-36.

VIRGILI, A. (|99|): L'expansió i afermament del feudalisme al Baix Gaià (segles XI i XII). Altafulla.

VIRGILI, A. ( 1995): "Visigots i àrabs. Segles V-XI". Catalunya Romànica. Barcelona, vol. XXI "El Tarragonès, el Baix Camp, l'Alt Camp, la Conca de Barberà, el Priorat", pp. 27- 35 y 47.

VIVES, E. (1989): "Estudi antropològic". in ADSERIAS et alii 1989, pp. 135-|49.

VIVES, E. (1990): La població catalana medieval. Orígen i evolució. Vic.

\section{RESUMEN}

Este artículo pretende ser una aproximación al mundo funerario medieval en la comarca de la Conca de Barberà, provincia de Tarragona (Cataluña). La existencia de un conjunto importante de necrópolis indica según el autor que la supuesta despoblación tras la conquista islámica no es cierta.

PALABRAS CLAVE: Conca de Barberà, Tarragona, Edad Media, necrópolis.
VIVES, E.; GIBERT, G. Ma. (1964): "Restes precistercenques a Poblet". Analecta Monserratensia X "Miscel-lània Homenatge a Anselm Ma Albareda" II, pp. 191-202.

YÁÑEZ, G.l. et alii (1994): "Excavaciones en el conjunto funerario de época hispano-visigoda de la Cabeza (La Cabrera, Madrid)". Pyrenae , 25, pp. 259-287.

ZAMORA, A. (1979a): "Datos en torno a la necrópolis de San Juan de los Caballeros en Segovia". Noticiario Arqueológico Hispánico , 6, pp. 58|-606.

ZAMORA, A. (1979b): "Excavaciones en el atrio norte de San Millán de Segovia". Noticiario Arqueológico Hispánico , 6, pp. 523-542.

\section{ABSTRACT}

This study is an aproach to the death world in the country of Conca de Barberà, Tarragona (Catalonia). There are a lot of medieval necropolis that show that the area isn't unpopulated after the islamic conquest.

KEYWORDS: Conca de Barberà, Tarragona, Middle Age, necropolis.

\section{POST SCRIPTUM}

Acaba de salir a la luz la publicación del Patrimoni Artístic Nacional d'Andorra, Roc d'Enclar. Transformacions d'un espai dominant. Segles IV-XIX (1997). En este estudio del yacimiento medieval mencionado en el texto se establece una nueva datación de la necrópolis, que hasta ahora se ha tomado como altomedieval. A partir de análisis radiocarbónicos ésta se data entre la Antigüedad Tardía y la Alta

Edad Media, sin que exista variación tipológica a lo largo del tiempo: caja de piedras, antropomorfa, cista de piedras, simple, fosa antropomorfa y fosa simple.

El estudio, pues, muestra una vez más que las dataciones "clásicas" de estos enterramientos necesitan una profunda revisión. 


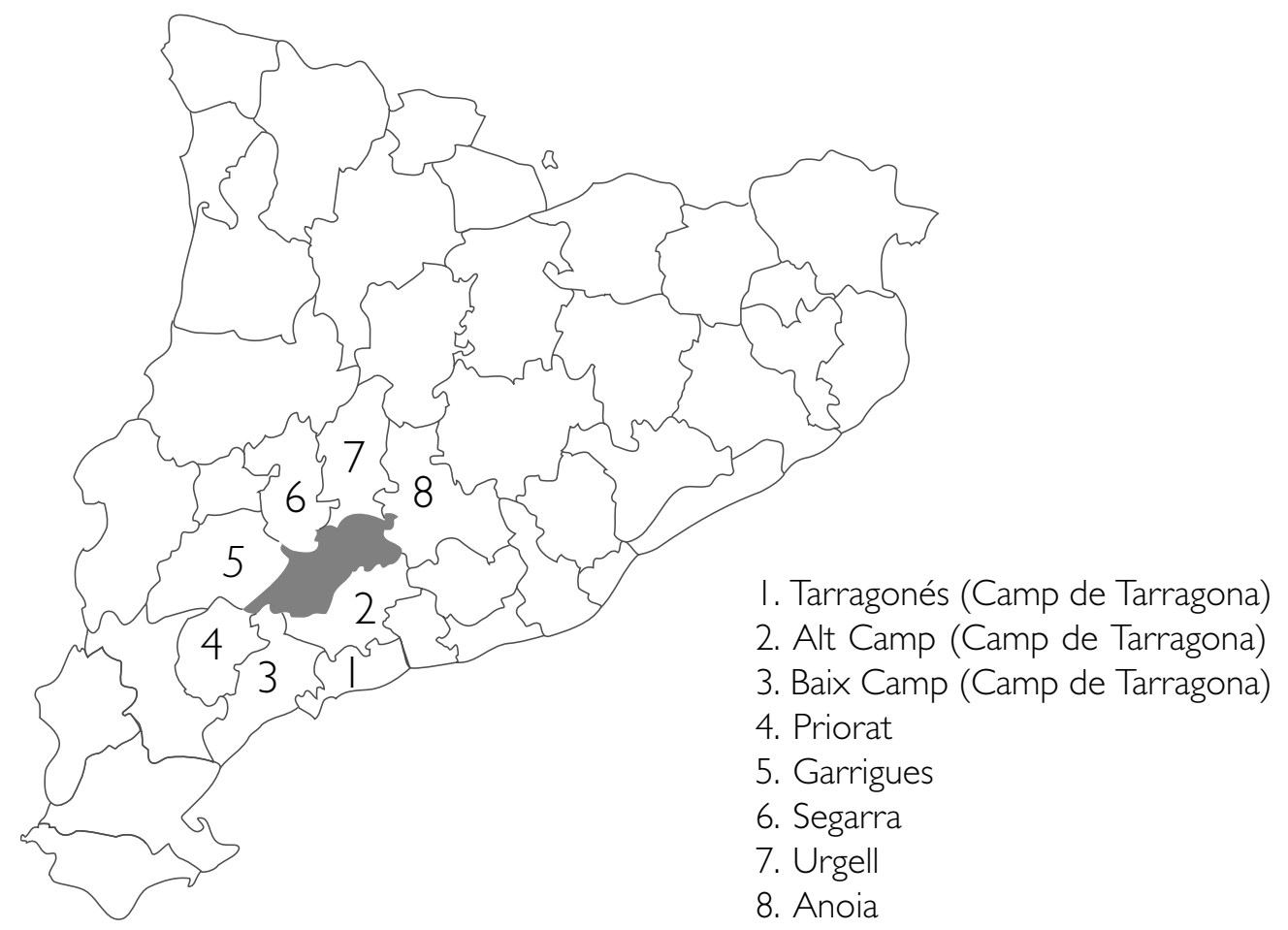

Fig. I. Localización de la Conca de Barberà en el mapa comarcal de Cataluña

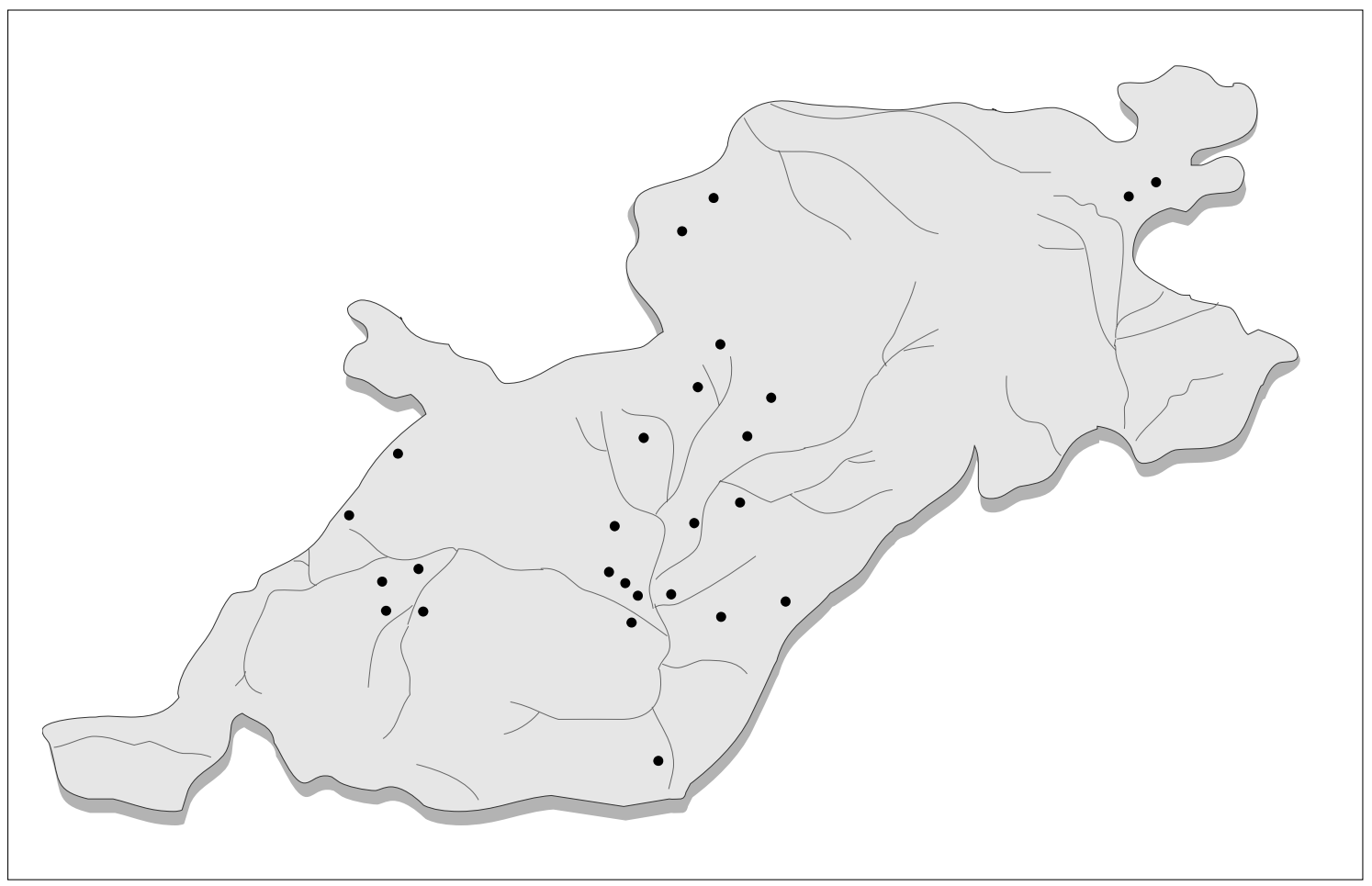

Fig. 2. Mapa de la Conca de Barberà con localización de las villas romanas actualmente conocidas. (Fuente, Museu-Arxiu de Montblanc) 


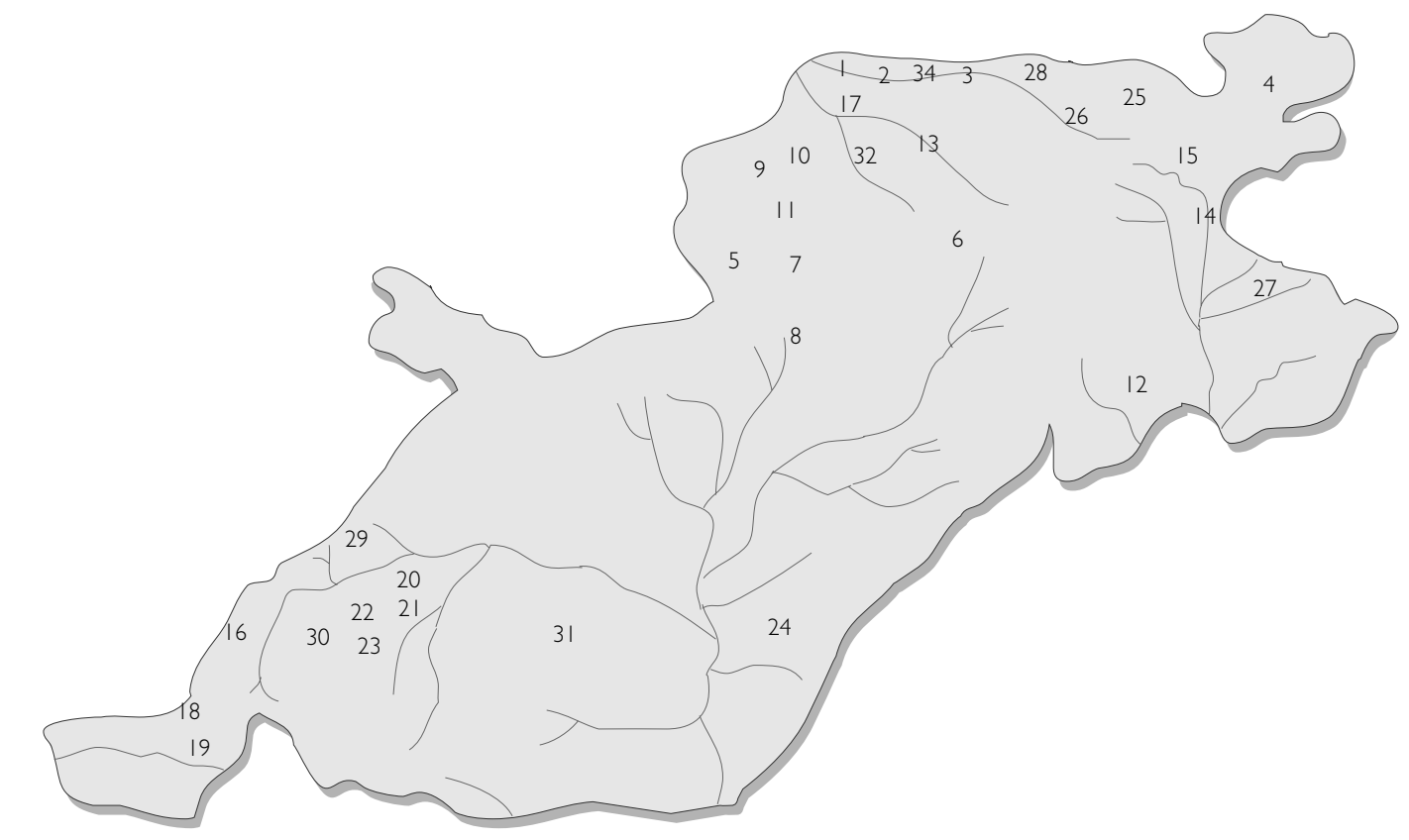

I. Albió: Tumba del Tossal. . 2. Albió: Tumba del bosque de la Devesa. 3. Albió: Tumba de la montaña de la Devesa. 4. Aguiló: Necrópolis cerca del Creu de Barràs. 5. Belltall: Necrópolis del Comestany. 6. Conesa: Necrópolis de las Comes. 7. Forès: Necrópolis de Coll de Ballestar. 8. Forès: Necrópolis Tuells. 9. Passanant: Necrópolis de las Roques de Dugo. 10. Passanant: Necrópolis de Vilars. II. Passanant: Necrópolis de la partida del Diumenge. I2. Pontils: Necrópolis de Mas Merí. I3. Segura: Tumba de Collado de Sadern. 14. Sant Gallard: Necrópolis de la Era del Carraca. I5. Santa Coloma de Queralt: Necrópolis del Gubià. 16. Vallclara. 17 Vallfogona de Riucorb. 18. Vilanova de Prades: posible Maqbara cerca del río Viern. (Francoli). 19. Vilanova de Prades: Necrópolis de la Nou, I' Anové o Anoué. 20. Vimbodí: Tumba de la Granja Mitjana. 21. Vimbodí: Necrópolis del Mas de la Cova. 22. Vimbodí: Necrópolis de Riudabella. 23. Vimbodí: Necrópolis del Tossal de les Forques o de Nerola. 24. Lilla. 25. Montargull. 26. L Cirera. 27. Riudeboix. 28. La Cirera. 29. Vimbodí (cerca de la autopista). 30. Vimbodí. 31. L' Espluga de Francolí (Coll del Sègol). 32. El Fonoll. 33. Forès, camino de Rocallaura. 34. Albió, camino a Savallà

Fig. 3. Mapa de la Conca de Barberà con situación de las tumbas y necrópolis de losa (Fuente, Museu-Arxiu de Montblanc y elaboración propia)
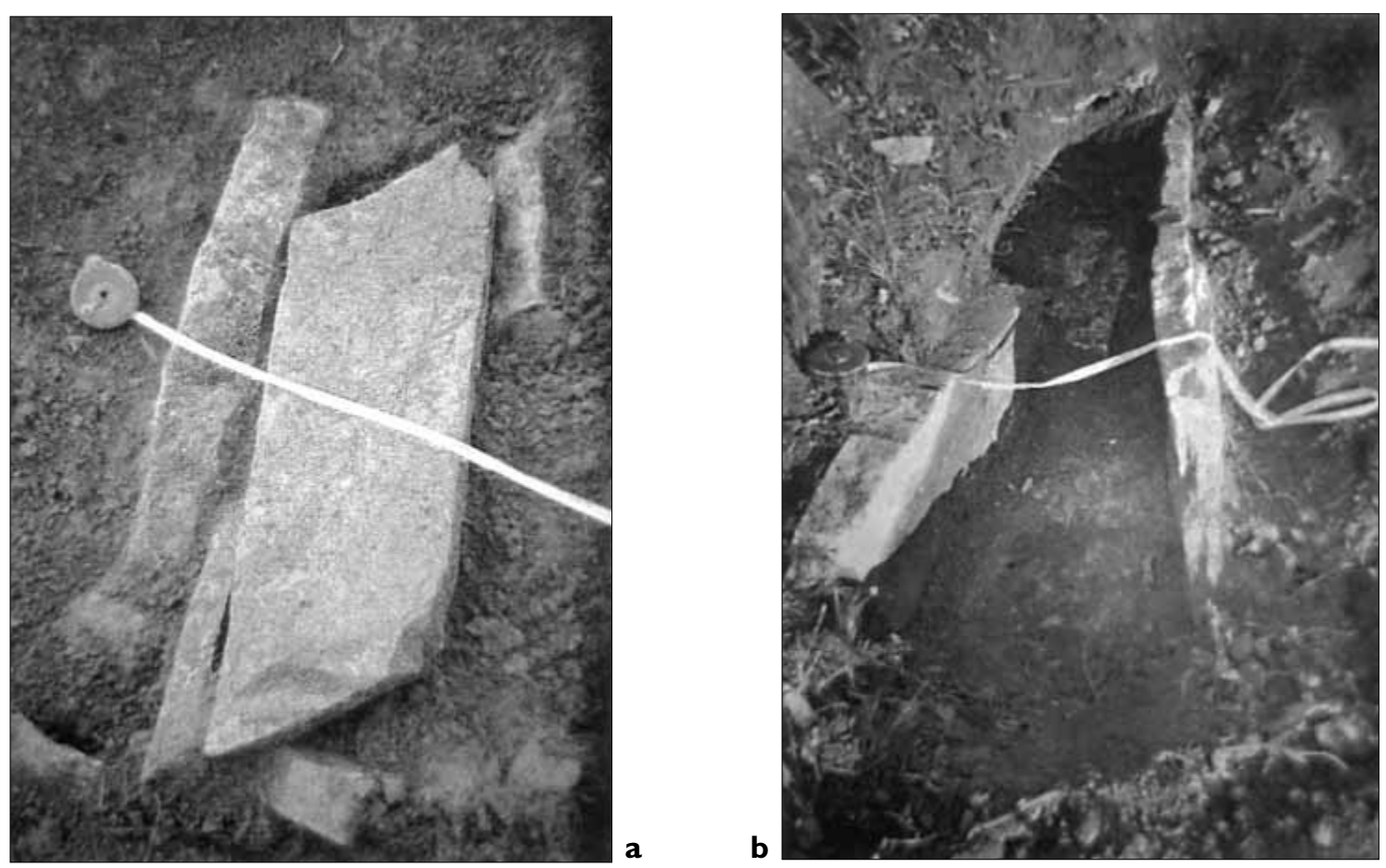

Fig. 4. Necrópolis de las Comes (según Vilaseca, Prunela 1966) 

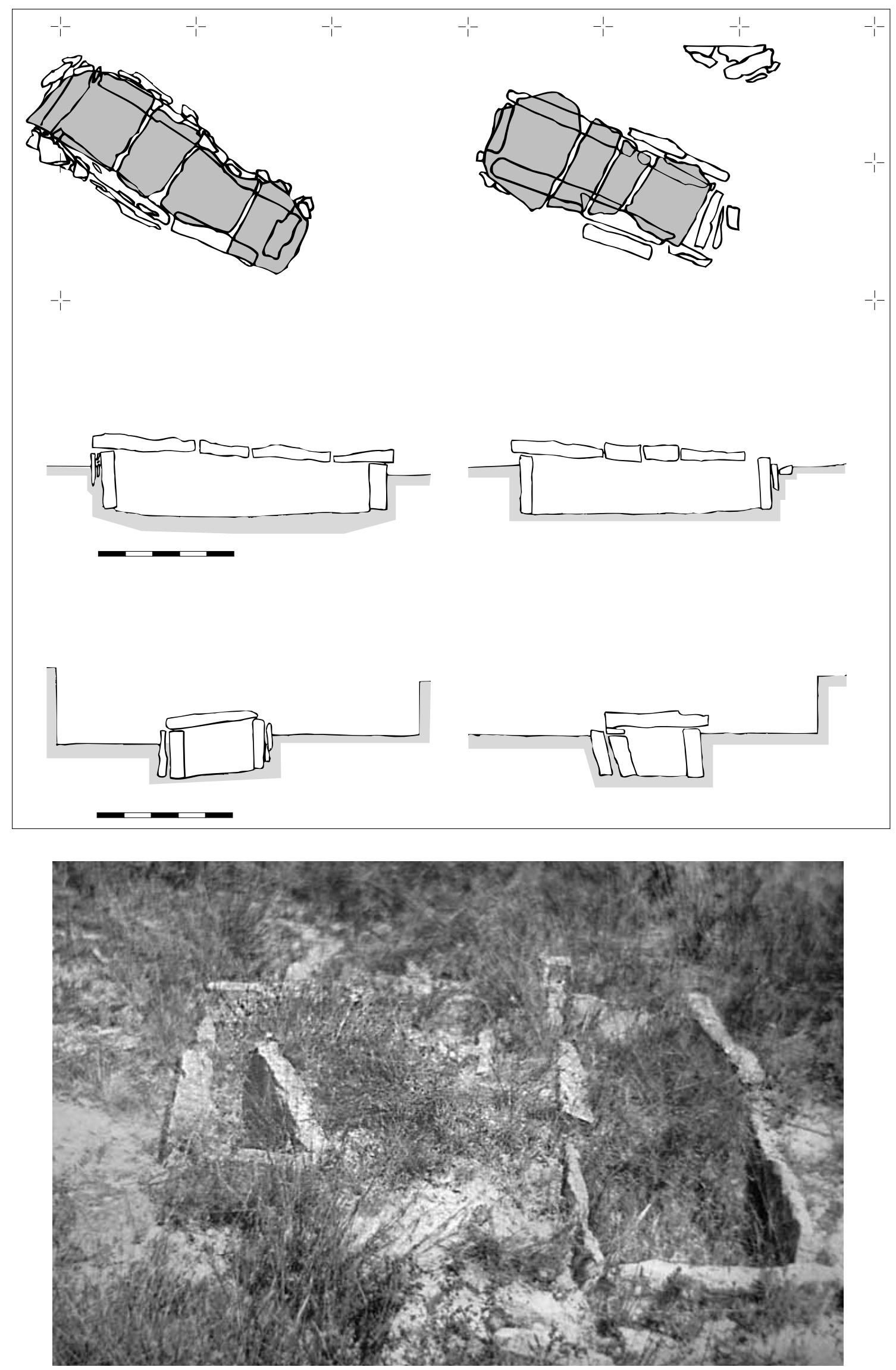

Fig. 5. Tumbas de la necrópolis de Tuells (según Gras, Ribas 1978) 


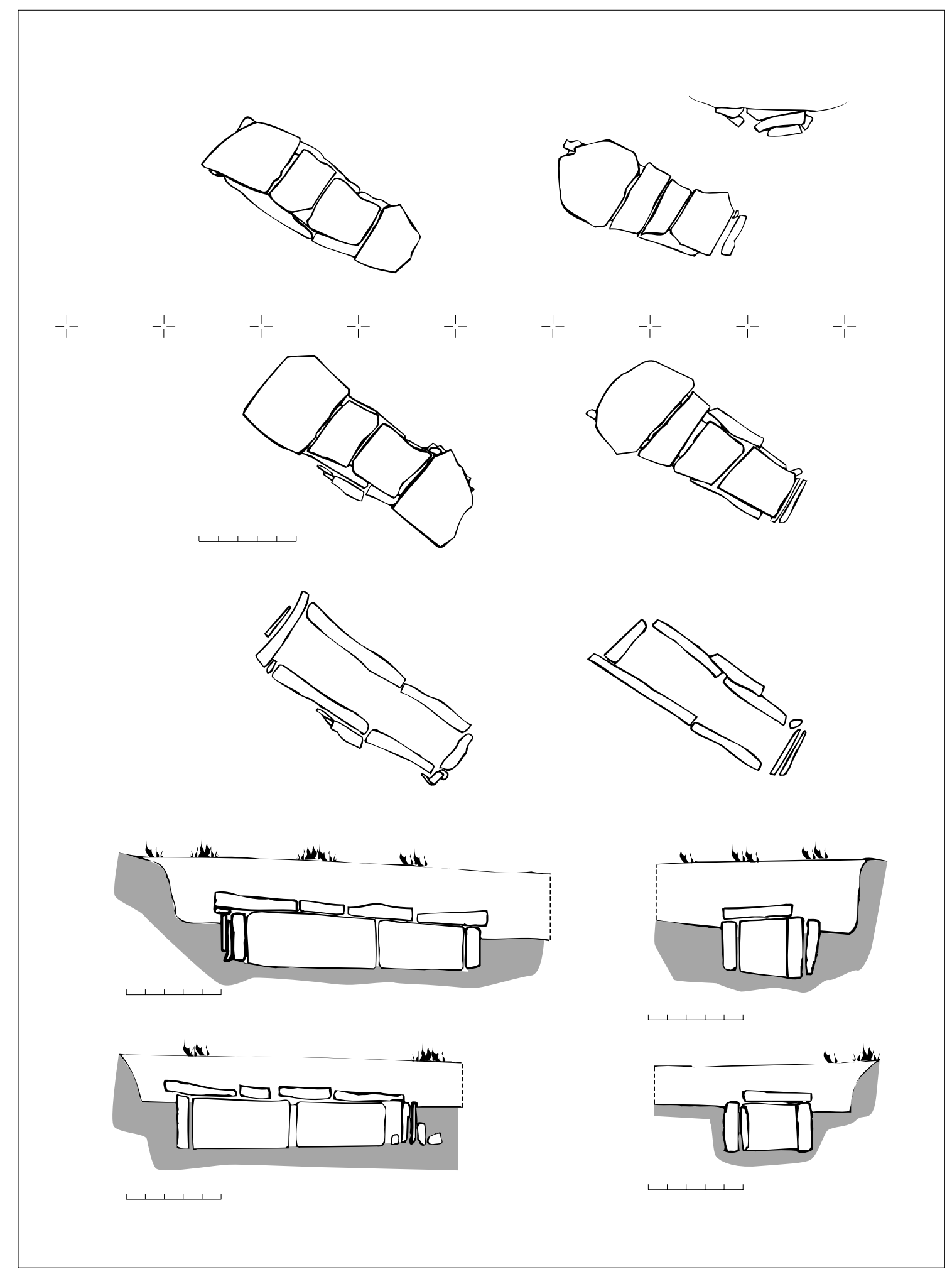

Fig. 6. Tumbas de las necrópolis de Tuells (según Batista, Ferrer 1993) 


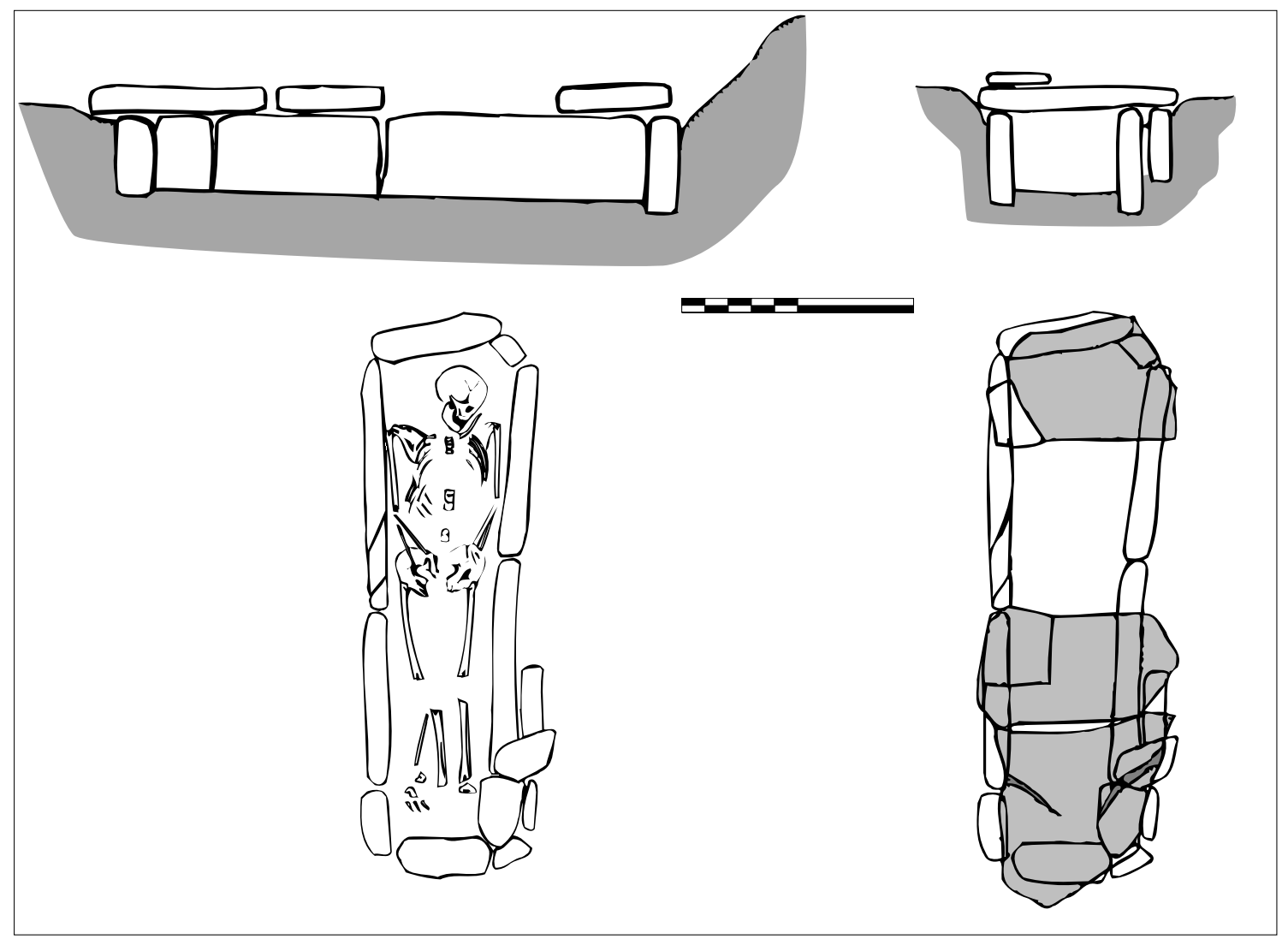

Fig. 7. Tumbas de la necrópolis de Tuells (según R. Farré-Servei d' Arqueologia de la Generalitat de Catalunya, publicada en Catalunya Romànica vol. XXI, 1995, p. 544)

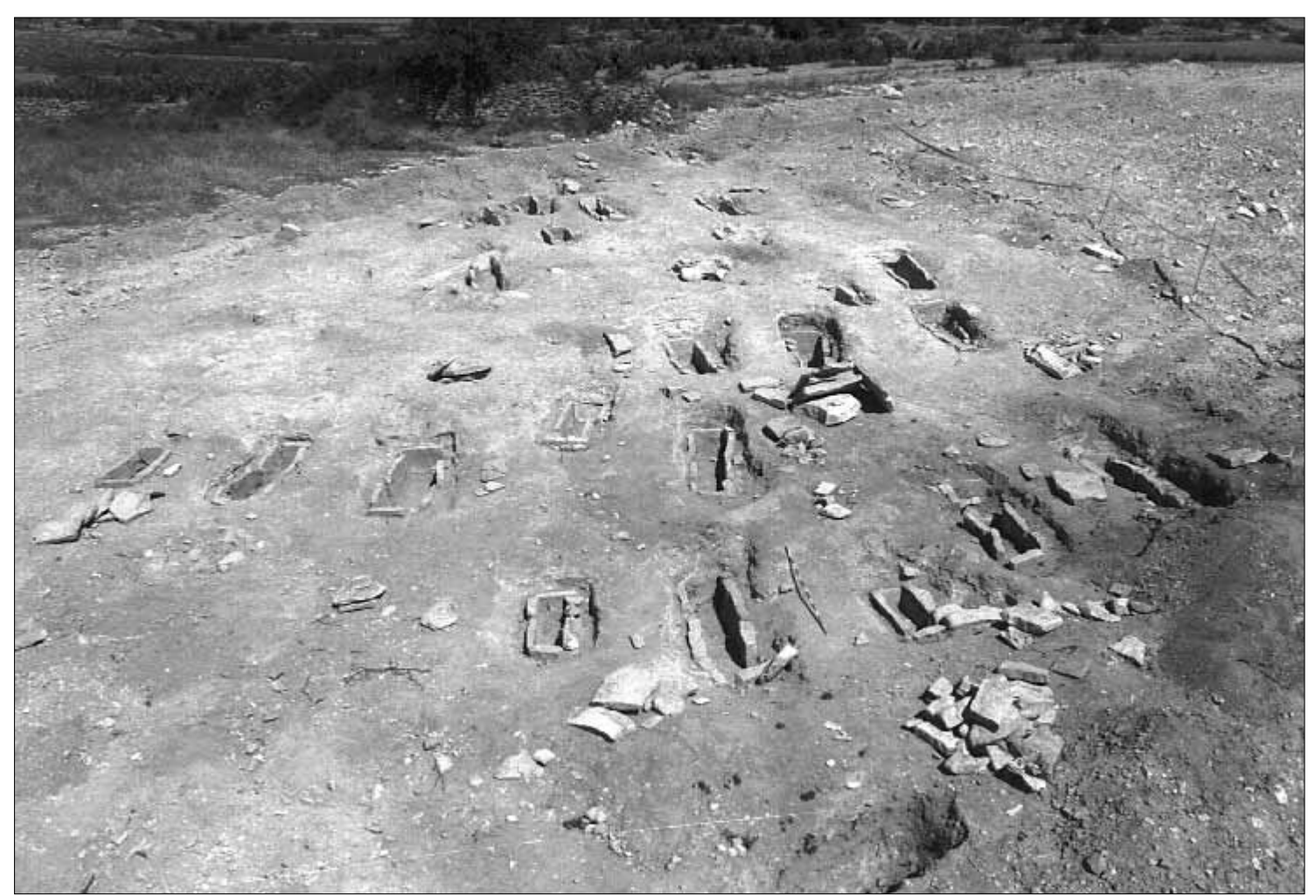

Fig.8. Vista de la excavación de la necrópolis de Tuells (Foto Maties Solé, Museu Arxiu de Montblanc) 


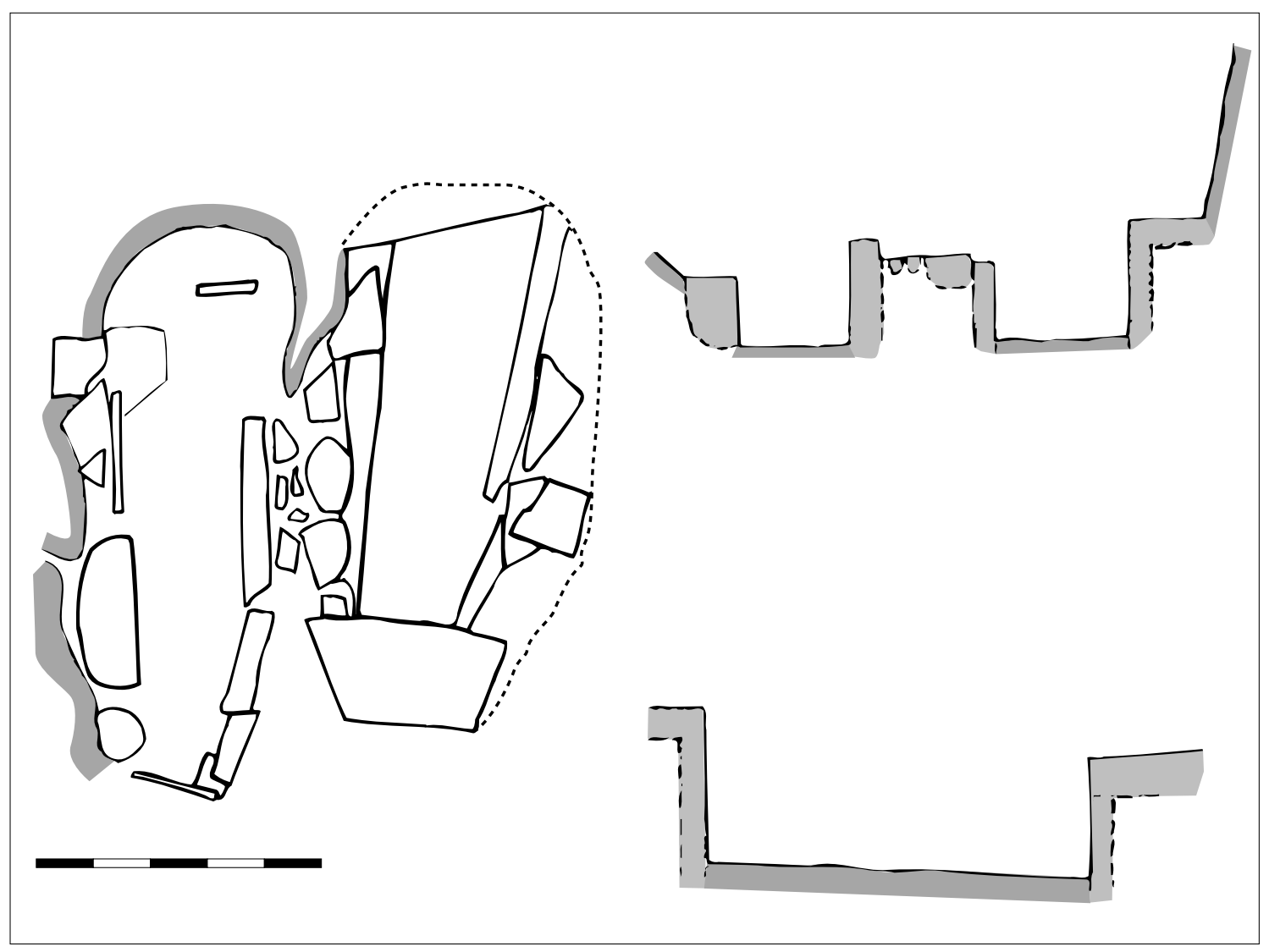

Fig. 9. Enterramientos del Tossal de les Forques, Vimbodí (según Adserias el alii 1989b) 